TI 2013-108/VIII

Tinbergen Institute Discussion Paper
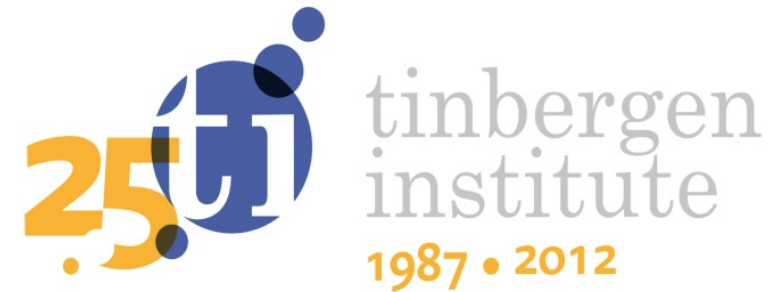

\title{
A Multi-Actor Multi-Criteria Analysis of the Performance of Global Cities
}

\author{
Karima Kourtit 1 \\ Cathy Macharis² \\ Peter Nijkamp ${ }^{1,3}$
}

\footnotetext{
1 Faculty of Economics and Business Administration, VU University Amsterdam, The Netherlands;

2 Vrije Universiteit Brussels, Belgium, and University of Gothenburg, Gothenburg, Sweden;

3 Tinbergen Institute, The Netherlands,
} 
Tinbergen Institute is the graduate school and research institute in economics of Erasmus University Rotterdam, the University of Amsterdam and VU University Amsterdam.

More TI discussion papers can be downloaded at http://www.tinbergen.nl

Tinbergen Institute has two locations:

Tinbergen Institute Amsterdam

Gustav Mahlerplein 117

1082 MS Amsterdam

The Netherlands

Tel.: +31(0)205251600

Tinbergen Institute Rotterdam

Burg. Oudlaan 50

3062 PA Rotterdam

The Netherlands

Tel.: +31(0)10 4088900

Fax: $+31(0) 104089031$

Duisenberg school of finance is a collaboration of the Dutch financial sector and universities, with the ambition to support innovative research and offer top quality academic education in core areas of finance.

DSF research papers can be downloaded at: http://www.dsf.nl/

Duisenberg school of finance

Gustav Mahlerplein 117

1082 MS Amsterdam

The Netherlands

Tel.: +31(0)20 5258579 


\title{
A Multi-Actor Multi-Criteria Analysis of the Performance of Global Cities
}

\author{
Karima Kourtit \\ Dept. of Spatial Economics \\ VU University Amsterdam \\ k.kourtit@vu.nl \\ Cathy Macharis \\ Dept. Transport and Logistics \\ Vrije Universiteit Brussels \\ University of Gotheborg \\ Cathy.Macharis@vub.ac.be
}

\author{
Peter Nijkamp* \\ Dept. of Spatial Economics \\ VU University Amsterdam \\ A. Mickiewicz University Poznan \\ p.nijkamp@vu.nl
}

\begin{abstract}
The strong world-wide urbanisation trend calls for a repositioning of cities, especially the large cities with a global impact. These cities tend to become economic, logistic and political powerhouses and are increasingly involved in a competition on their integral performance. The present paper aims to trace to what extent and why some cities outperform others. Starting from an extensive database on many important characteristics of global cities, this paper offers a multi-criteria methodology for identifying the relative position of various important cities on the basis of distinct assessment criteria. The explicit consideration of the perceptions of important classes of stakeholders on the performance outcomes of the various cities involved allows for a enhanced policy analysis. From a technical assessment perspective, the applied part of the paper employs the MAMCA and PROMETHEE multi-criteria methodology, which have proven their analytical power in various multi-criteria evaluation problems over the past years. The paper concludes with some policy perspectives and lessons.
\end{abstract}

Keywords: Urbanisation, global cities, multi-criteria analysis, performance, stakeholders, MAMCA, PROMETHEE, GAIA

* Tinbergen Institute, The Netherlands 


\section{Aims and Scope}

In our urban century the majority of the people on our planet will live in cities. Urban agglomerations tend to become the ultimate 'destiny' of mankind, with unforeseen challenges for urban research and policy. In the 'new urban world'(see Kourtit and Nijkamp 2013) dominated by connected large cities and urban networks, our society will face serious concerns related to housing, sustainable modes of living, poverty, employment, accessibility, competitiveness, and economic vitality.

World-wide, cities are increasingly seen as engines of economic growth and sustainable development (see Nijkamp 2008). This strategic importance of modern cities - and increasingly, urban agglomerations and metropolitan areas including polynuclear or satellite areas - does not only depend on location advantages (including Marshall-Arrow-Romer (MAR) spatial externalities), but also on two other types of externalities, viz. social capital externalities and connectivity externalities. The first category has been well described by Jacobs (1969) who has introduced the concept of an urban 'melting pot': cities house a multiplicity of people with different cultural, ethnic or language backgrounds which may at times create tensions, but also form the seedbed conditions for innovative and creative behaviour (see e.g. Florida 2002). The second type of externalities is based on economies of connectivity - either physical connectivity through e.g. road or airline networks or virtual connectivity through global information or internet networks (see e.g. Taylor 2004, Tranos and Nijkamp 2013).

The changing scene of cities - from an island position to a nodal position in global networks - has brought about a series of challenges and concerns on cities of the future (see e.g. Blanke and Smith 1999, Hall 2004, Jacobs 2012). According to Nanetti (2012), a strategic vision of future cities calls for the following traits in urban development: territorially-specific, futureoriented, problem-solving, strategically-informed, operationally-translated and politicallycommitted. There is indeed a need for a strategic perspective on 'sustainable urbanism' (see Diappi 2012, Farr 2008, Healey 2007), in which urban gentrification, culture, creative land use, accessibility and ecological sustainability play a central role.

Clearly, the specific favourable facilities and social capital conditions of modern cities tend to induce more creativity and profitability. A spatial concentration of activities, involving spatial and social proximity, increases the opportunities for interaction and knowledge transfer, while the resulting spillover effects reduce the cost of obtaining and processing knowledge. In addition, knowledge workers preferably interact with each other in agglomerated environments so as to reduce interaction costs, while they are more productive in such environments. It is therefore, no wonder that cities become the cradle of new and innovative industries. Innovative firms based on advanced services in the early stages of the product and company life cycle - when dealing with 
a manifold uncertainty - prefer locations where new and specialized knowledge is abundantly available at low costs (see e.g. Audretsch 1998, Camagni 1991). Cities offer in this context an enormously rich potential for a wide array of innovative business opportunities.

Another major megatrend in human settlement patterns is noteworthy in this context, viz. a structural rise in urbanisation in the past centuries. Our world has turned into an urban world, with more than half of the world population living in cities nowadays (see also Kourtit et al. 2012). And the urbanisation degree is still on a rising edge, notably in Latin America, Africa and Asia. This megatrend does not only mean a quantitative change in the share of inhabitants in urban areas in the national territory, but also a qualitative transformation of both a socioeconomic and political nature. Modern network cities have turned into spearheads of (supra)regional and (supra-)national power, not only from a socio-economic perspective (business, innovativeness, jobs, wealth), but also from a geo-political ('cities as global command and control centres'; see Sassen 1991) and a technological perspective.

To meet a wide array of future challenges and opportunities, urban agglomerations and their business operations have to be smart and resilient. And therefore, over the years modern global cities have dramatically changed the way of managing dynamics in urban development in order to become and remain an attractive environment for various stakeholders, for example, in attracting and retaining firms or tourists and in recruiting talented people in a vibrant urban environment. To that end, appropriate support systems for a creative business environment need to be developed, and more resources for sustainable growth need to be provided. Repositioning of modern global cities calls for a solid evidence-based benchmarking analysis (see Begg 1999).

A major question is now: which are the critical parameters that may serve as policy handles for a successful urban development? The road towards economic growth, social inclusion and environmental sustainability of a city is not easy to achieve. In recent years, the concept of a 'smart city' has gained increasing popularity and has prompted a great deal of policy attention and research interest (see e.g. Caragliu et al. 2011, Winters 2010). In a recent paper by Nam and Pardo (2011), a list of smart cities all over the world can be found, while also various definitions of a smart city - and conceptual relatives of a smart city (e.g. digital city, learning city) - are recorded and described. A main issue in analyzing smart cities - or related concepts - is: what makes a city smarter than another city?

The above question has prompted much empirical research on ranking of cities in our world, such as the Economist Intelligence Unit addressing liveability of cities. Obvious caveats in comparing the performance of different cities are: differences in city size, the number of and type of indicators used, the sample of cities chosen, the goal of the interurban comparison etc. In the present study we will compare the performance of various world cities based on a set of extensive and carefully collected indicators. In a relatively short time, this set of indicators - 
known as the GPCI (Global Power City Index), provided and updated on an annual basis by the Mori Memorial Foundation in Japan (2012) - has become a unique source of scientific research on cities world-wide (see e.g. Kourtit et al. 2012).

Our study aims now to offer an in-depth analysis of the GPCI database on 40 world cities (see Section 2). It offers a comparative benchmark assessment of these cities by investigating their detailed performance indicators on the basis of a recently developed multi-criteria model coined MAMCA (see Section 3). This methodology enables the explicit consideration of the perceptions and priorities of various distinct classes of stakeholders. The results of this experiment are presented and interpreted in Section 4, while Section 5 offers some policy perspectives and lessons.

\section{Description of the Database}

Cities are engines of economic power but also nodes in global networks. They need each other, but are also each other's competitors. The combination of internal strength and external orientation determines the growth potential and economic position of cities (see Neal 2012). Cities operate in an international playing field and, hence, their socio-economic performance may show much variation. The question is then: why do some cities outperform others? This idea formed the basis of the creation of the above-mentioned GPCI database. This database contains extensive information - in numerical form - of many world cities which are evaluated and ranked according to their 'magnetism', e.g. their competitive power to attract creative people and business enterprises from all over the world. This open access database is carefully validated through field visits and in-depth reports. It contains a wealth of multi-annual data on major critical indicators - and a very detailed list of sub-indicators - for economic strength of the relevant cities contained in the database. At present, this data system has accurate information on 40 world cities ranging from New York to Istanbul, and from Tokyo to Geneva. In addition, a similar database has been created for 9 Japanese cities that were not included in the overall data bases, for instance, Sapporo, Yokohama, Nagoya or Kobe. This extensive GPCI database offers also the possibility for benchmarking of each individual city, in terms of strength and weakness regarding each individual performance indicator.

Thus, the GPCI aims to offer systematic and comparative information on the comprehensive economic position of major cities in the world, and it does so by focussing on a wide variety of functions performed by the cities under consideration. For each individual city, 6 main classes of functions were carefully mapped out and numerically assessed, viz. economy, research and development, cultural interaction, liveability, environment and accessibility. In addition, the importance of these indicators was carefully assessed by 5 distinct groups of 
stakeholders, viz. managers, researchers, artists, visitors and residents. The summary results from the 2012 GPCI rankings are contained in Figure 1.

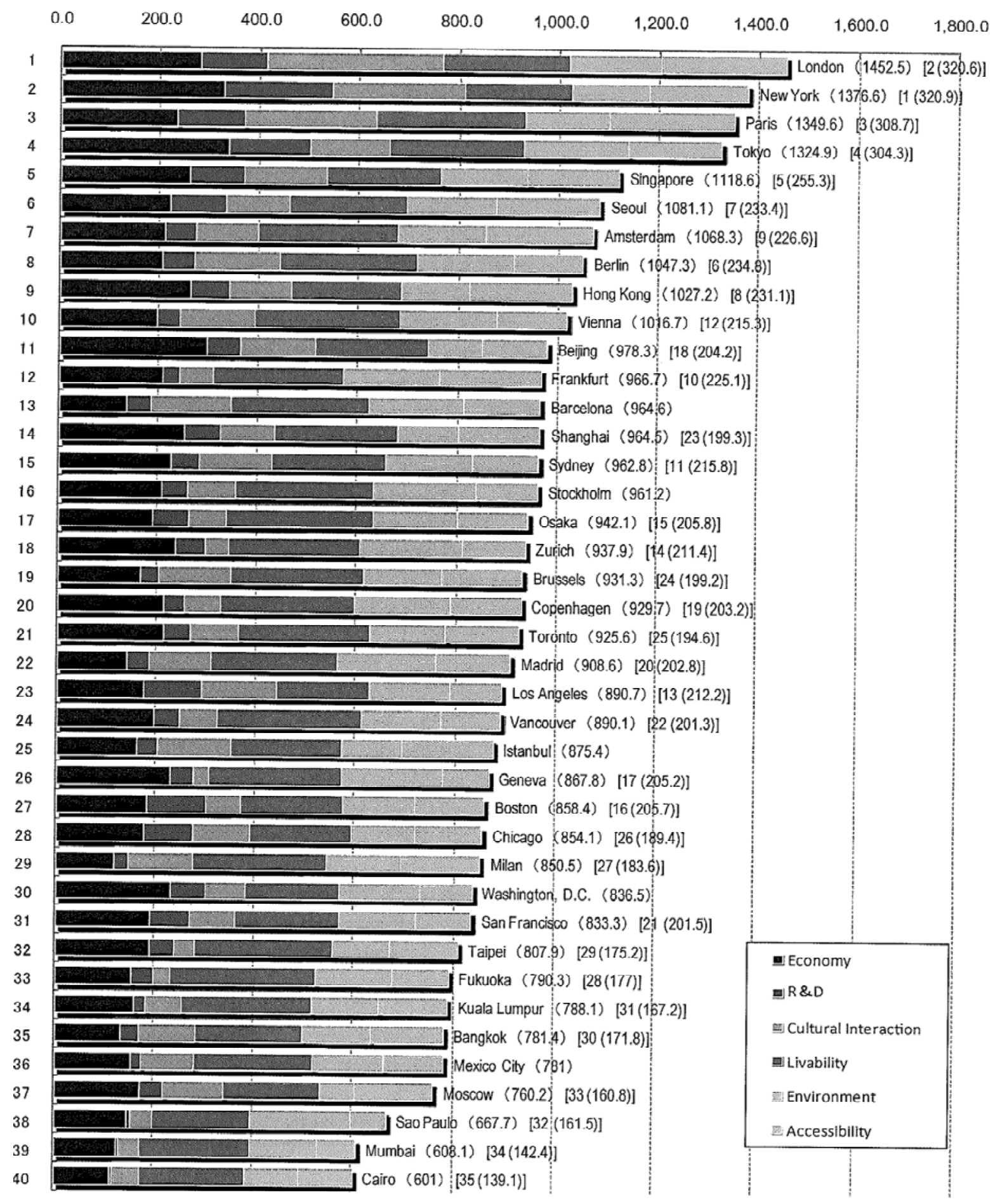

*Numbers in [ ] are scores/ranks from the GPCl-2011

Figure 1. Comprehensive scores and ranking of 40 global cities by 6 functions

Source: Mori Memorial Foundation (2012) 


\section{Results of the MAMCA Model}

Our study has tried to identify the potentially most powerful global city - measured in terms of 6 main criteria and a vast set of subcriteria - by applying an appropriate multi-criteria model, coined MAMCA. MAMCA is a member of the family of multi-criteria analysis methods which have gained much popularity over the past decades. It has also often been applied in urban and regional evaluation methods (see, e.g. Nijkamp et al. 1991, Munda 2006). The MAMCA (in full, Multi-Actor, Multi-Criteria Analysis) model allows not only to perform a multi-criteria analysis on the basis of standard information on alternatives and choice criteria, but also to include preference elicitation through an explicit involvement of relevant stakeholders (Macharis 2004, Macharis et al. 2009). MAMCA is a methodology, a stepwise structured approach to analyse the opinions of these stakeholders. The data from the GPCI system are very suitable for the MAMCA approach, as they include the criteria and the underlying indicators for each actor together with the importance these actors are attaching to a specific criterion. Within our evaluation methodology, different multi-criteria analysis (MCA) techniques can be used. In this paper we show the possibilities of two frequently used and related MCA methods, namely the Analytical Hierarchy Analysis (AHP) method (or Saaty method) and the PROMETHEE method in order to analyse the GPCI data (Macharis et al., 2003). We have chosen these two methods as they belong to two different MCA schools, namely the American (AHP) and the European school (PROMETHEE). Both methods have found extensive application in the MCA literature (see Behzadian et al. (2010) for an overview of applications with PROMETHEE and Ishizaka and Labib, (2011) for AHP).

We will first illustrate the use of MAMCA by addressing the relative performance profiles of 8, rather arbitrarily chosen cities from our GPCI set. By the use of expert choice software (in distributive mode), supporting the use of the Analytical Hierarchy Process method developed by Saaty (1982), the data of GPCI (2012) for the cities of London, Paris, New York, Tokyo, Singapore, Amsterdam, Berlin and Brussels were selected, taking into account the observed preference intensity of various classes of stakeholders regarding these cities.

The meaning of the MAMCA analysis will be clarified by means of Figure 2, in which the viewpoint for the category "visitor" is shown. On the horizontal axis the criteria of this class of actors are shown. The height of the bar shows the weight the class of visitors is attaching to the respective criterion concerned. The left axis gives the scales of these weights. On the right axis, the scores of the cities on the criteria provided by the class of visitors can be seen. The overall ranking is also shown. This overall ranking is a weighted sum of the specific score on each of the criteria, while taking the weights into account. London, Paris and New York are clearly ranked 
on a top position for this actor. However, all cities have clear positive performance outcomes, but amongst these also elements in which they can improve their performance. The dining possibilities in Tokyo really stand out, for example, while its mobility (in particular, accessibility) leaves room for improvement. What is also becoming obvious from this figure is that some criteria are clearly differentiating between the cities, like dining or cultural interaction, while other criteria like safety are quite similar for all cities.

Next, when we bring the points of view of all classes of stakeholders regarding these 8 cities together in a multi-actor profile (as shown in Figure 3), we can again observe some very interesting elements. In this graph the different categories of actors are shown on the horizontal axis. If all actors receive an equal weight, then Paris, London and New York all end up at a top position, but one can clearly see also differences in achievement. Researchers appear to prefer New York, while artists would prefer Paris. Tokyo is in the middle, followed by a lower group with Berlin, Singapore, Amsterdam and Brussels. Berlin, Amsterdam and Brussels appear to show the same pattern with always the same ranking, but Singapore is clearly very attractive for doing business, but clearly, much less attractive for the class of artists.

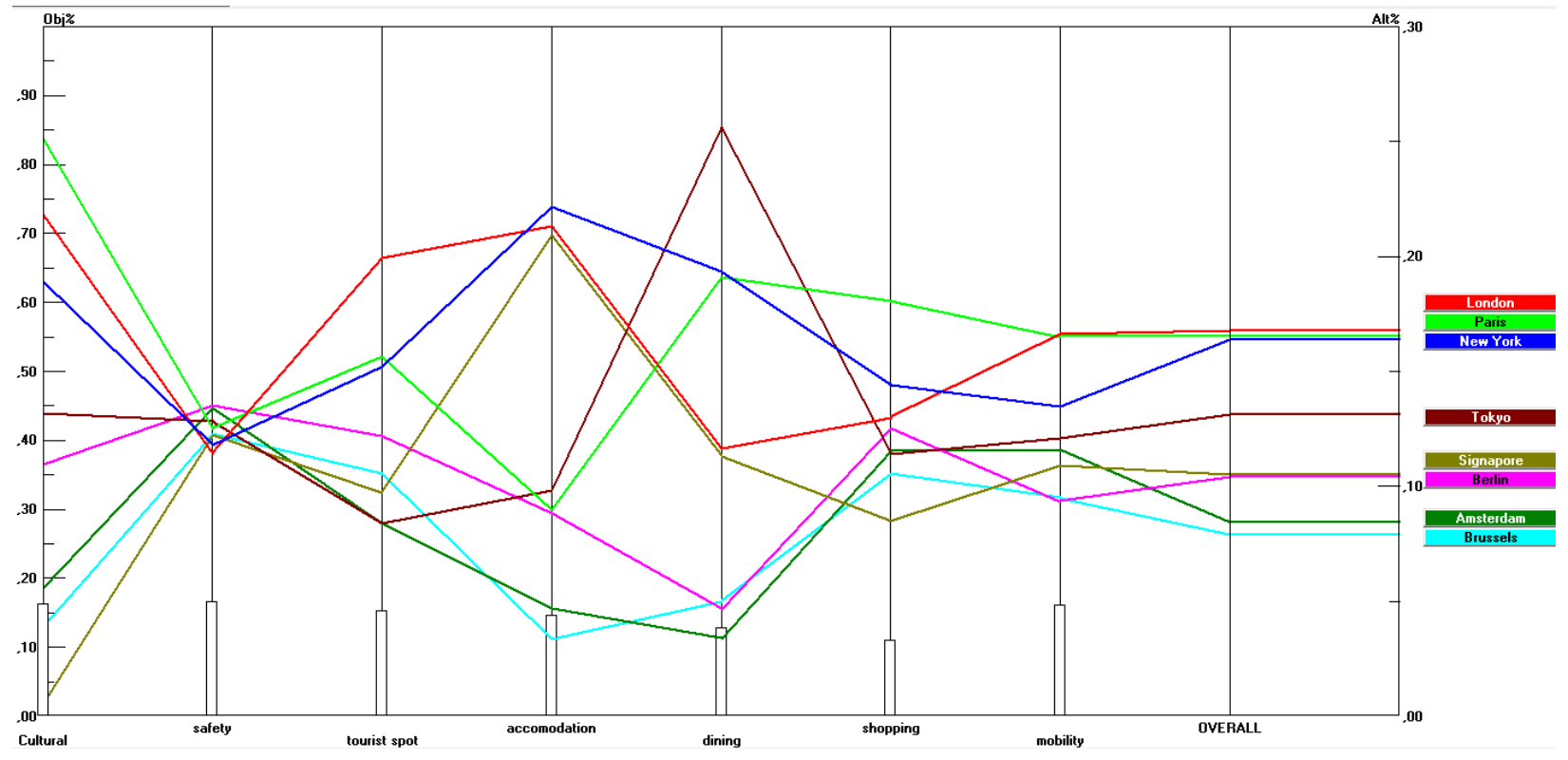

Figure 2. MAMCA results for 8 world cities from the perspective of the class of 'visitors' 


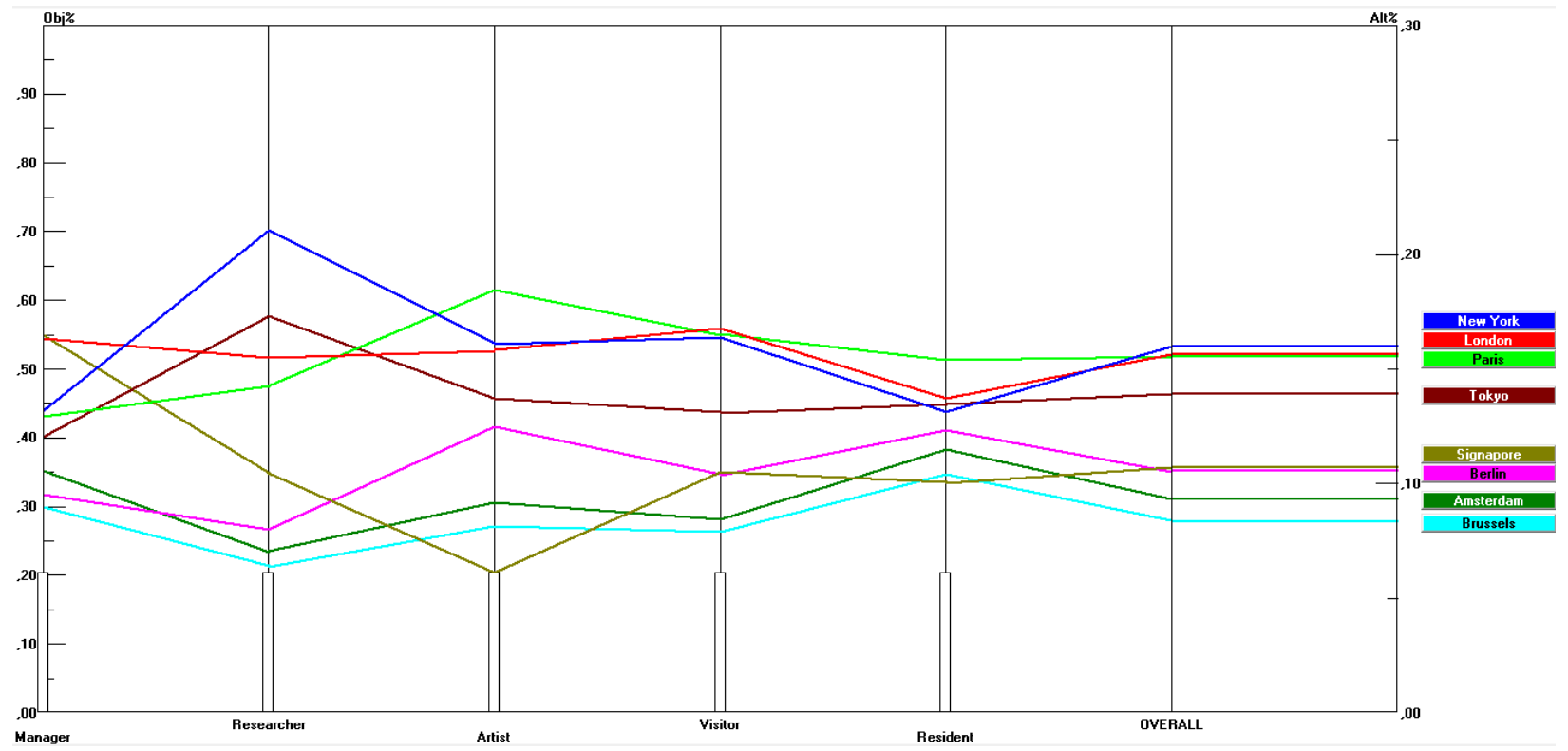

Figure 3. MAMCA results for 8 world cities from the perspective of all classes of stakeholders

The advantage of the MAMCA model is that it has the potential to offer the strengthweakness profiles of various choice alternatives, seen from the perspective of both different judgment criteria and different groups of stakeholders. Clearly, if the number of choice options is very large (like in our case, 40 cities), it becomes somewhat cumbersome to present all outcomes in one graph. But any specific subset of interesting choice alternatives can of course be taken and mapped out in the respective graphs. In the remaining part of this section we will offer the results from various other interesting combinations of cities in order to illustrate the power of the MAMCA approach.

It goes without saying that several sensitivity analyses are also possible with the MAMCA model, for instance, by adding all cities from the GPCI database, by zooming in on size classes, on continents, specific stakeholders or specific criteria. Also the stakeholders can be given different weights, for example give more weight to the opinions of the residents compared to the artists. So a complete sensitivity analysis is possible. If we make a selection of the top-10 most efficient cities from the GPCI database - with a selection made on the basis of a recently undertaken DEA-analysis; for details, see Kourtit et al. (2012), - the multi-actor analysis shows that for each class of actors New York and Tokyo are really on top of and far above the others (see Figure 4). For the remaining 8 cities we see that they exhibit different profiles. For example, Hong Kong appears to have a very high ranking for managers, but less so for artists. 


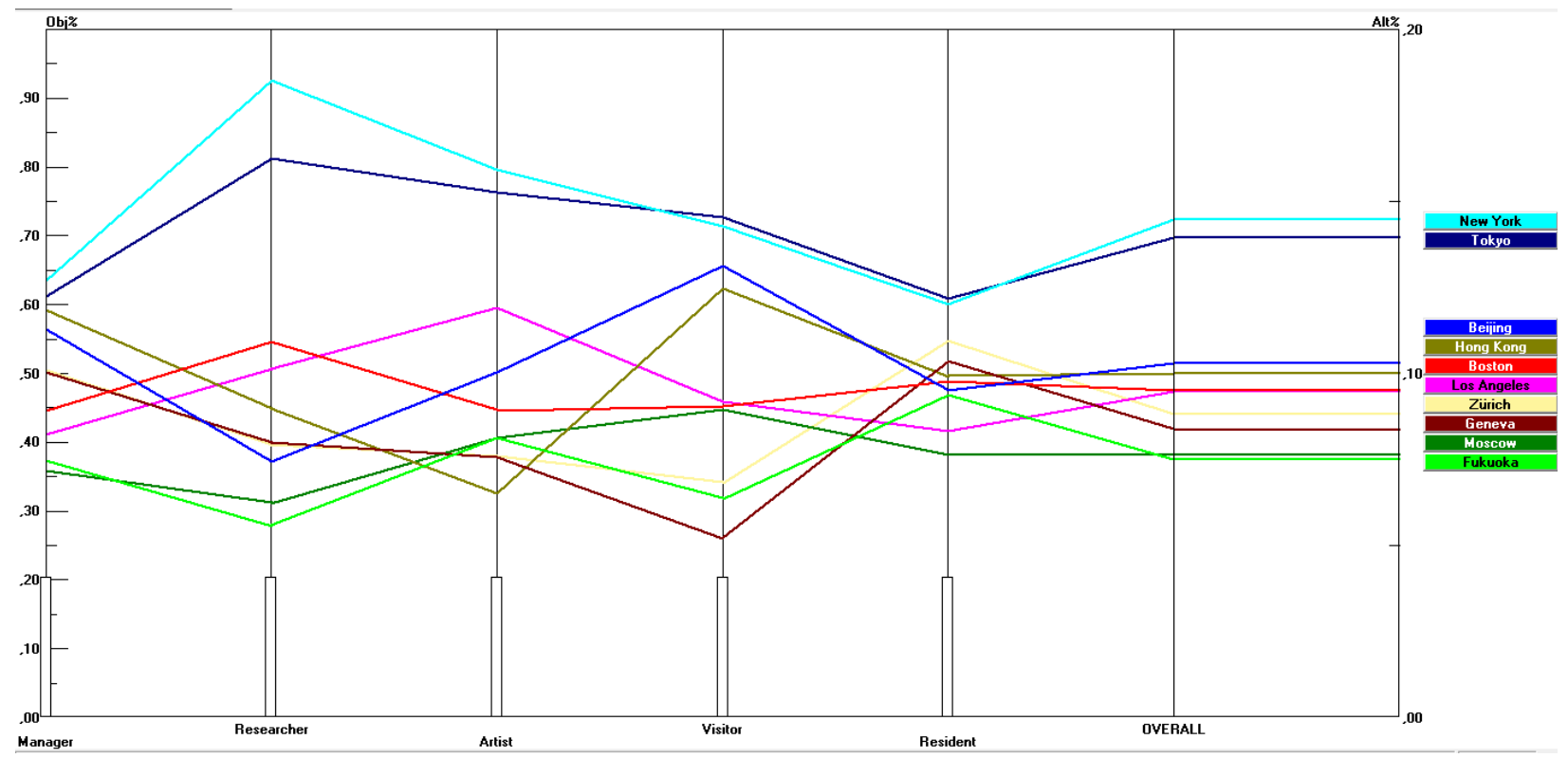

Figure 4. MAMCA results for the top-10 most efficient world cities from the GPCI database, from the perspective of all classes of stakeholders

It may be added that also for the class of top-10 GPCI cities the strength-weakness profile for a given class of stakeholders, for example, the class of visitors, can again be mapped out, so that a more detailed view on the positive and negative aspects of a city for that specific actor can be provided (see Figure 5). This figure also shows which criteria might be really differentiators. The more the scores are dispersed, the more this criterion is differentiating among distinct judgement criteria, for example, high class accommodation; on the other hand, mobility (including accessibility), a criterion which receives a large weight by the class of visitors, appears to discriminate less in the different cities considered here. Furthermore, safety is certainly a criterion for which the cities which score high on most of the other criteria, are not performing so well. 


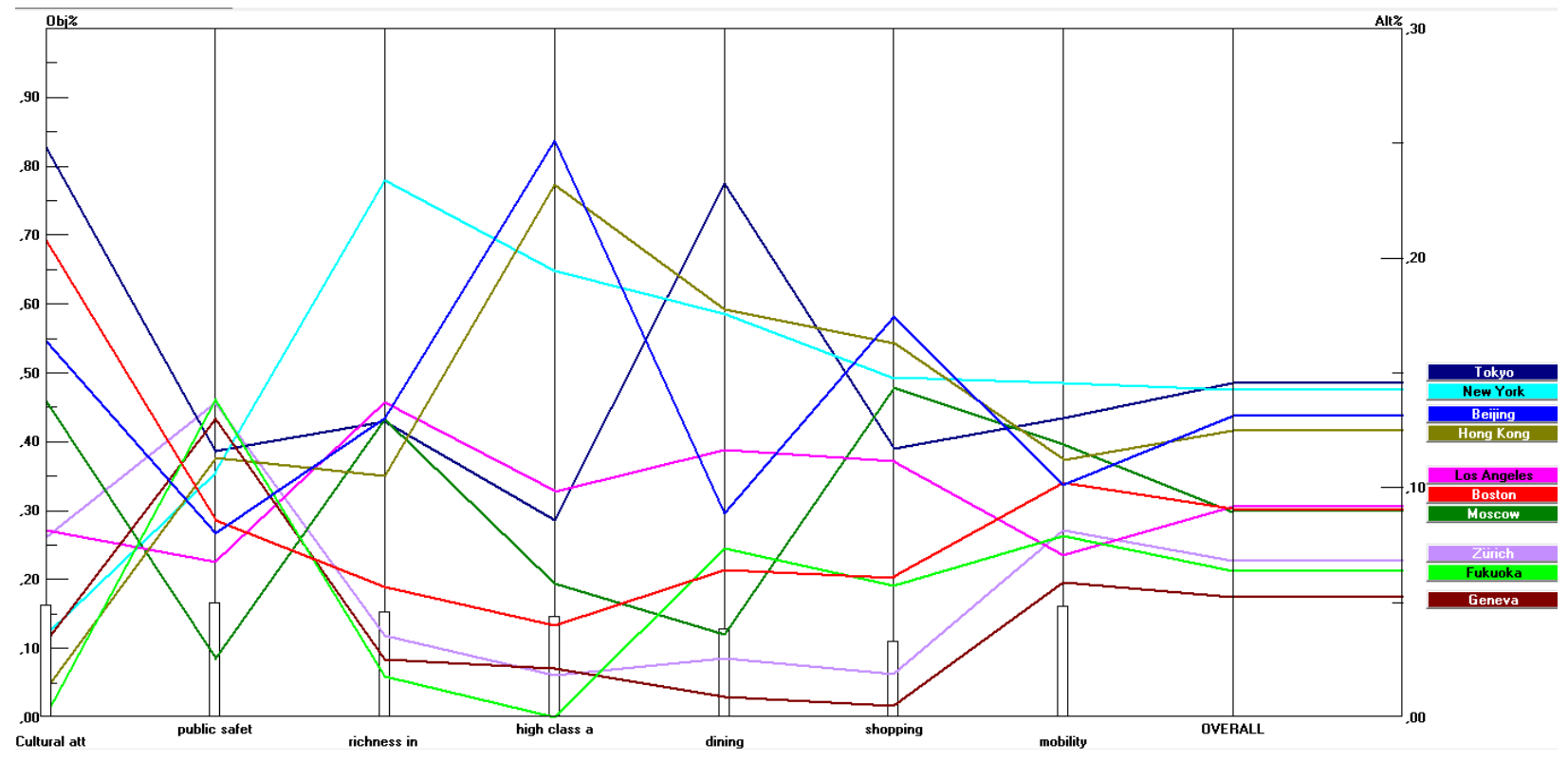

Figure 5. MAMCA results for the top-10 most efficient world cities from the perspective of the class of 'visitors'

For the 10 lowest scoring cities - in terms of efficient performance - in the DEA analysis executed by Kourtit et al. (2012), a similar analysis is next executed, where Paris acts essentially as a benchmark for the others. We present here (see Figure 6) only the overall results, seen from the perspective of all classes of stakeholders. This figure is similar in contents to the above presented Figure 4. It appears that Paris is clearly standing out in this class of lower ranked cities. Clearly, although it is not an efficient city, it has several advantages for different actors.

The clearly differentiating nature of the MAMCA model results can be shown by focussing the attention, for example, on the class of 'artists'. In this respect, Paris takes the clear lead in its importance of a cultural and artistic centre, far above all other cities in this subset of GPCI cities (see Figure 7). 


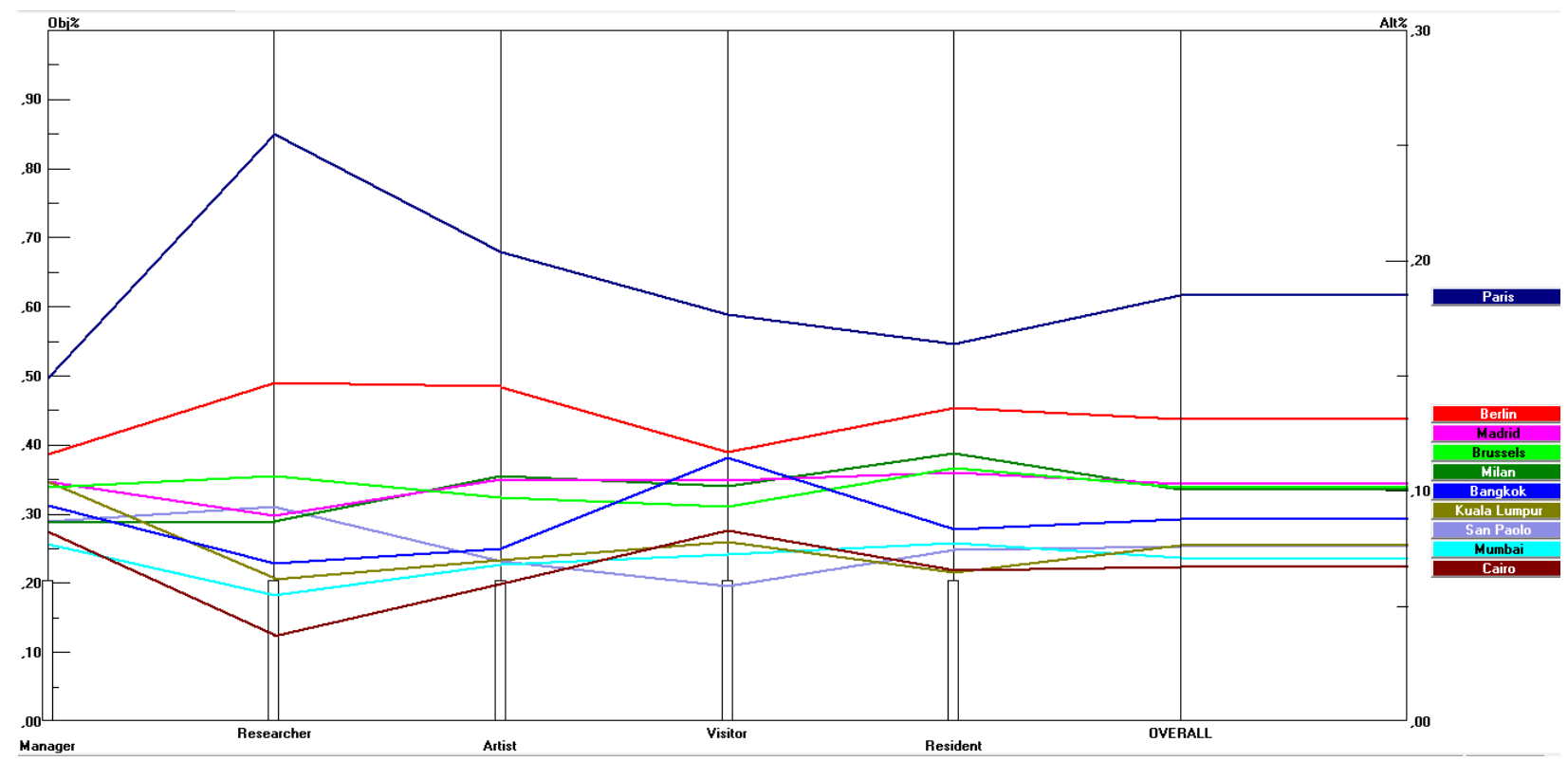

Figure 6. MAMCA results for the bottom-10 world cities - in terms of efficiency - from the perspective of all classes of stakeholders (with Paris as a benchmark)

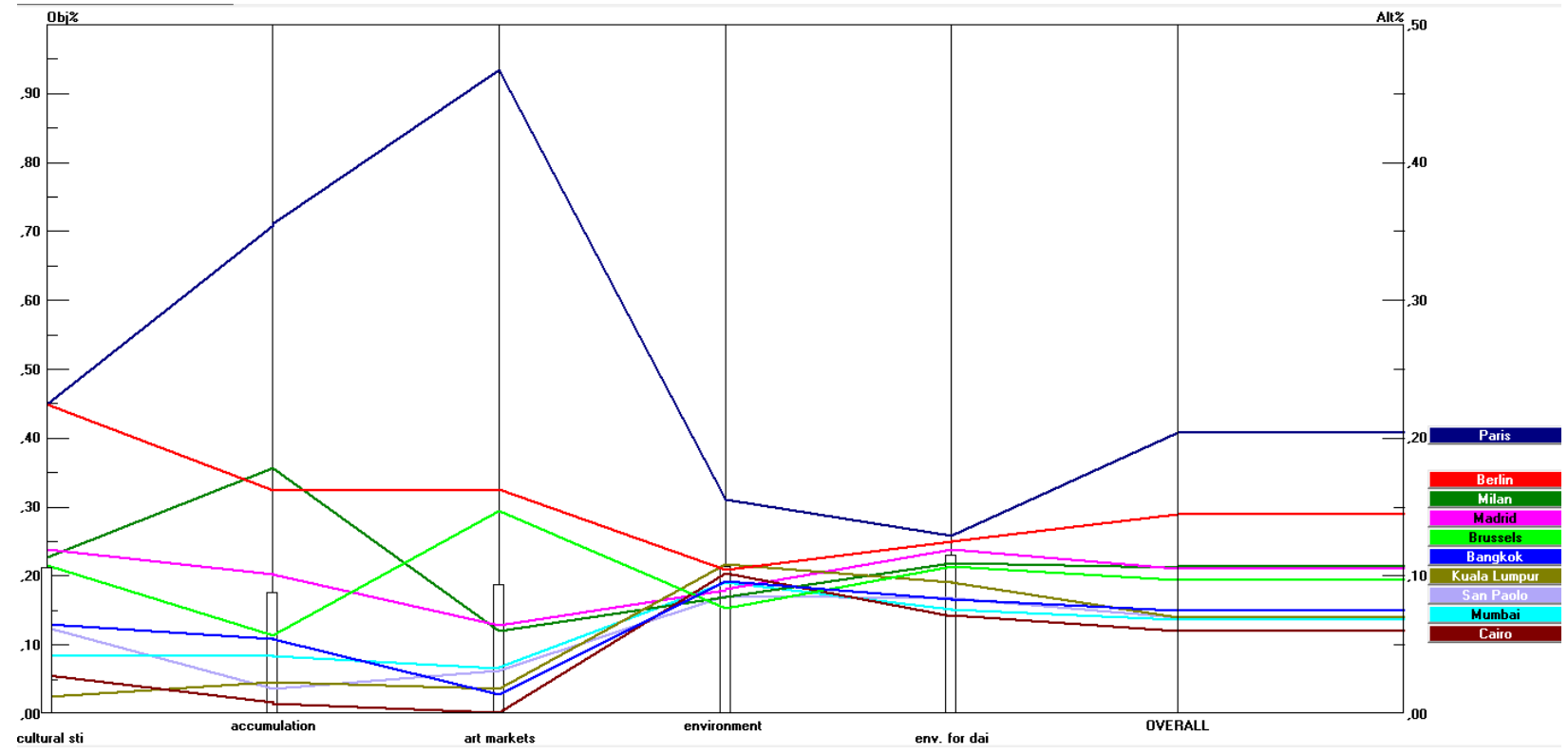

Figure 7. MAMCA results for the bottom-10 world cities - in terms of efficiency - from the perspective of the class of 'artists' (with Paris as a benchmark)

The MAMCA model offers clearly a broad perspective on the factors determining the perceived performance of world cities. An often heard complaint in the use of multi-criteria analysis (MCA) for evaluating choice alternatives is that the results may be sensitive to the MCA method chosen. To clarify the scope of such a multi-criteria method, we have therefore used 
another MCA method, the so-called PROMETHEE approach (see for details Brans and Mareschal 1994) and its extension towards group decisions (see for details Macharis et al. 1998).

This method - and in particular the so-called GAIA variant - is able to link the total performance evaluation of relevant alternatives to the various classes of stakeholders. In using the PROMETHEE software called D-Sight, different analysis methods can be used. We will present here the results of a specific technique, the GAIA method. The GAIA (Geometrical Analysis for Interactive Aid) plane is a two-dimensional visual representation of a decision problem in which the alternatives and their contribution to the various criteria are simultaneously displayed. In a multi-actor setting, GAIA will show the points of view of the different actors in the plane. Additionally, a decision stick can be used to further investigate the sensitivity of the results as a function of weight changes (see Brans and Mareschal 1994).

The GAIA method plots the different cities in a two-dimensional space by using a principal component analysis. Each axis represents the point of view of each of the actors concerned, while the decision axis (the red axis) shows the cities which overall have the highest score. For the sake of illustration, in the next graph, a comparison is made between the EU cities (the yellow ones) and the non-EU cities (the purple ones) within the top-10 cities of the GPCI database (see Figure 8). 


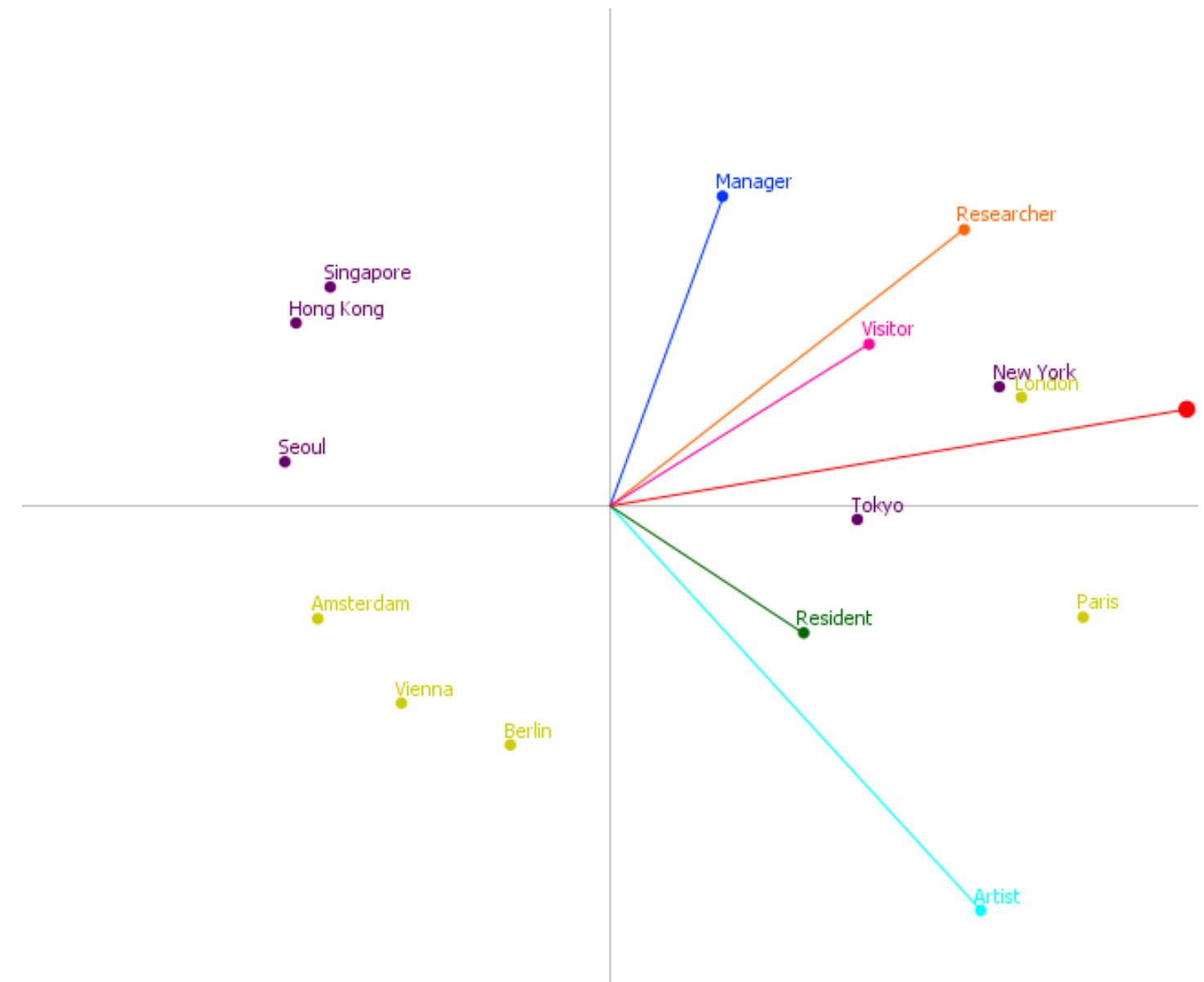

Figure 8. GAIA plane with topological positions for the selected EU and non-EU top-10 cities

It is interesting to see that the actor axes in Figure 8 are pointing to the right, meaning that the perception of stakeholders on the performance of the cities is not completely opposite. The points of view appear to deviate most between artists and managers. The decision axis is pointing in the direction of New York, London and Tokyo. Most of the European cities are situated at the lower level, showing that these are interesting places for staying there as residents or artists.

Clearly, such types of analysis can be carried out for different cities and perspectives in our database. A similar analysis can, for instance, be done with a distinction between mega-cities versus non-megacities, OECD countries versus non-OECD countries, and so forth. All such experiments allow to identify what the contribution is of each of these points of view to the overall score.

Such ranking analyses can be undertaken for various subsets, such as the top-10 cities in our database, discussed above (see Figure 9). Then, it turns out that Paris, London, New York and Tokyo are clearly ranked in the top. The contribution of each of the actors is equally divided. Singapore has quite an unique profile. It scores very good for managers, but not that good for artists. In this graph it is clear that the points of view of the visitors and researchers are very 
close to each other. If we look at the scores on the criteria of these two actors, we see indeed that there is quite a high correlation between them.

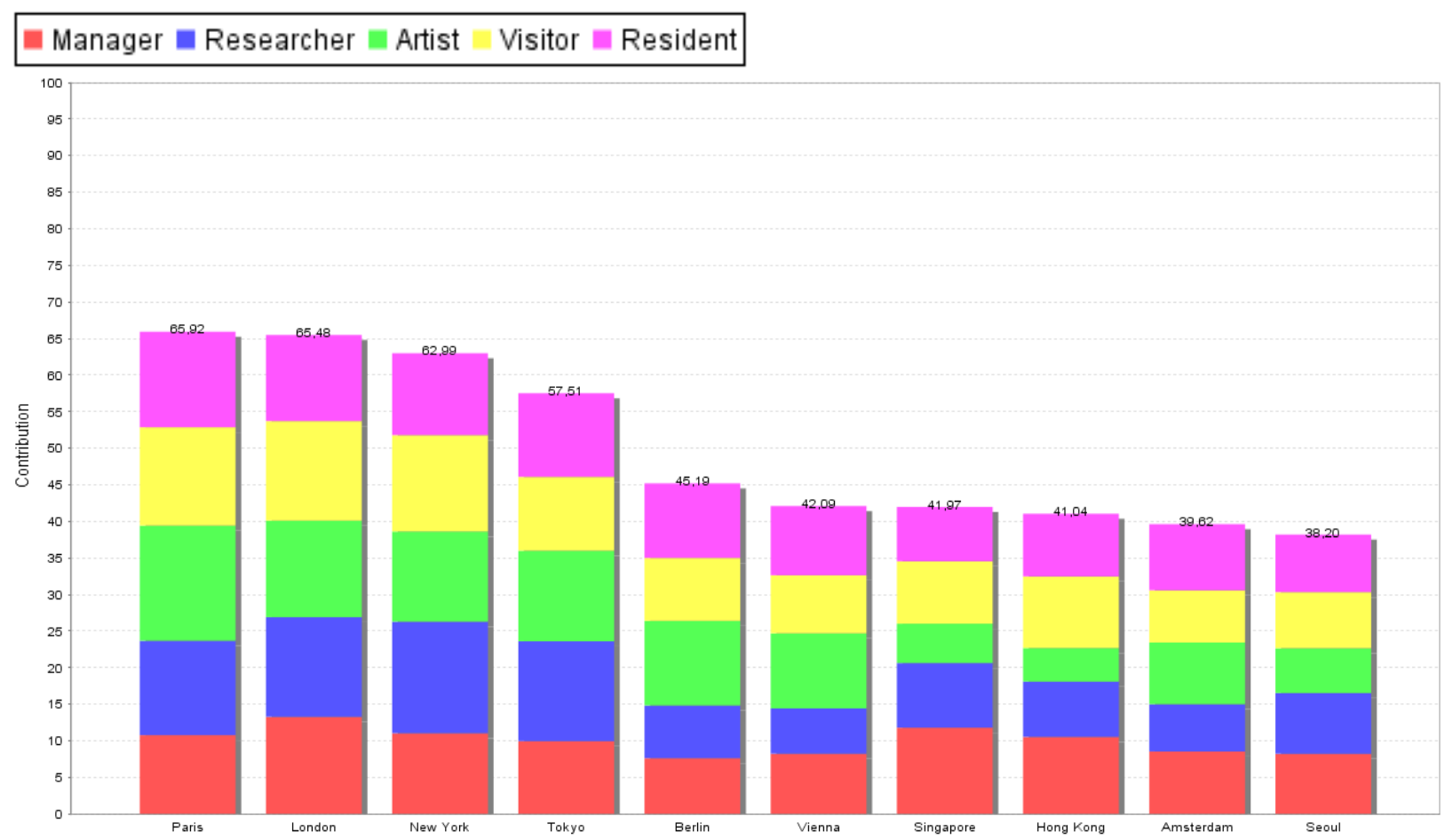

Figure 9. Overall ranks of the top-10 cities on the basis of the PROMETHEE method

In addition to achieving the rankings of cities based on a combined multi-stakeholdermulti-criteria approach, it is also possible to identify the closeness between clusters of cities through an appropriate cluster algorithm based on an A-versus B-analysis. In Figure 10 the two classes of actors 'visitors' (A) and 'researchers' (B) are compared to each other. The higher the correlation between the two criteria the more the cities would be located near the diagonal line. We see that for these two classes of actors, the correlation is not that high, meaning that these actors have quite differentiated and independent objectives/criteria. 


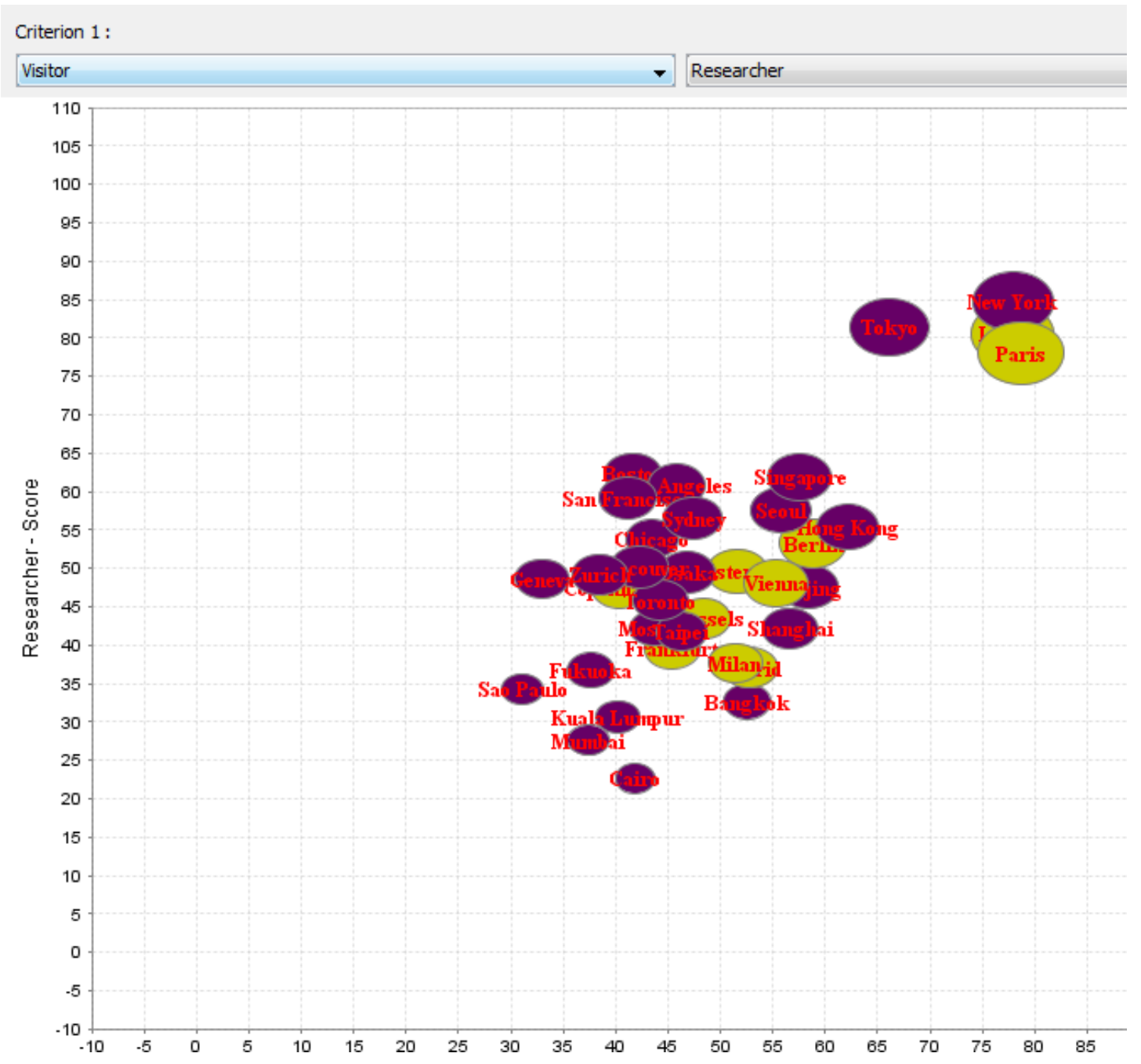

Figure 10. A (visitor)- versus B (researcher)- analysis with all cities (green: EU countries, purple: non-EU countries).

Comparisons of individual criteria between actors are also possible. An obvious but illustrative example in our modeling approach is a combined analysis of two attraction factors, viz. the concentration of artists (a social network criterion for artists) and cultural attractiveness of a city (an attractiveness criterion for visitors). Figure 11 shows that this correlation is indeed very high, as the cities are located near the diagonal. This kind of analysis can show the most prominent and interesting interactions between the criteria at hand. So if a city is addressing one of them, this will indirectly also lead to an interesting increase of the scores for another related actor. 


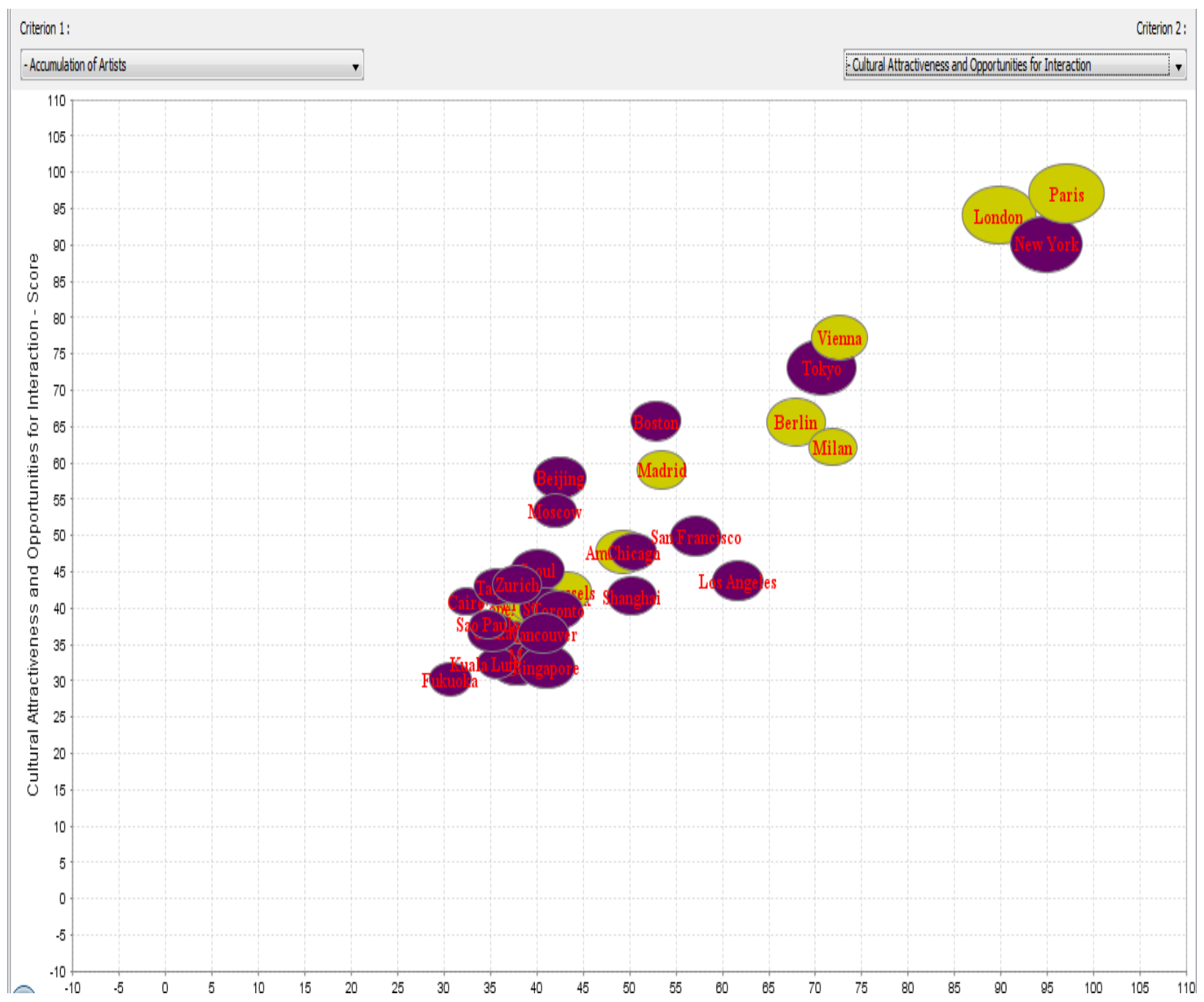

Figure 11. A (concentration of artists)- versus B (cultural attractiveness)- analysis for all cities

If we compare the PROMETHEE method with the AHP method for a MAMCA application to the GPCI data, we may conclude that they are quite complementary. In Figure 12, we show the analysis for the same 7 randomly selected cities as considered above for AHP. The GAIA plane appears to show better the points of view of the different actors and how the cities can be clustered according to these points of view. For example, New York, London, Tokyo and Paris are situated on the positive side of the plane (in the direction of the decision stick). Paris scores better for residents and artists, while New York and London score higher for researchers and managers. Also for the cities that have a lower score, important findings can be extracted from these visual presentations. For example, Singapore scores good for managers, but less so for artists, a conclusion we have also drawn from the AHP analysis. 


\section{Policy Lessons}

The above analysis has brought to light important findings on the relative position of major cities in our world. Apparently, if we look at the rankings of all cities for each individual main indicator, there is no unambiguous winner in all dimensions. In multi-objective programming terms: there is no single super-efficient solution in the set of alternatives (see Rietveld 1980). But there are several cities which score higher on all indicators than others. These cities may be called dominant cities, as they outperform all the others. Clearly, the results may change, if different groups of stakeholders attach different priorities (weights) to the various main indicators.

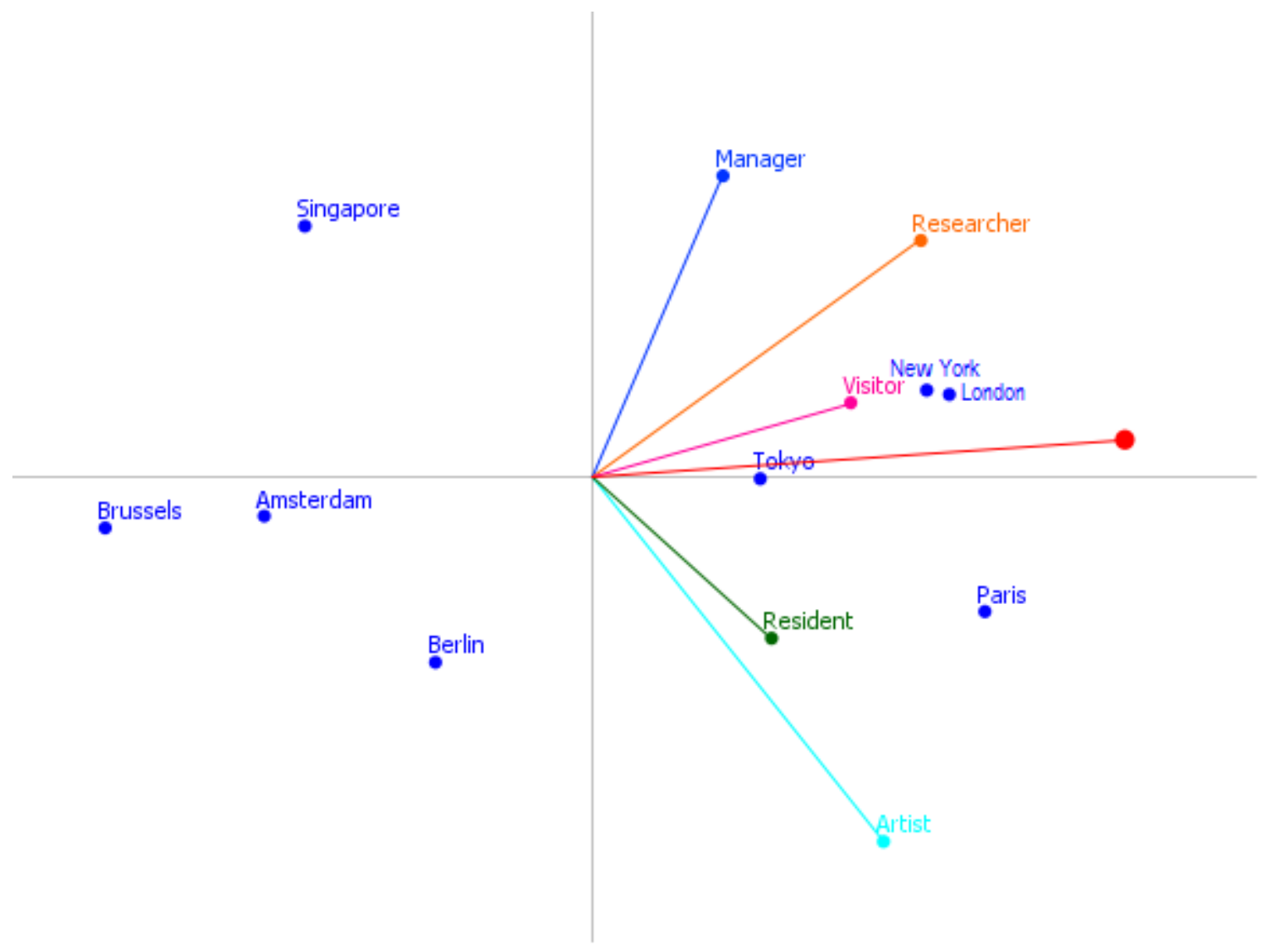

Figure 12. GAIA plane for 7 world cities, as compared to Figures 2 and 3

Cities can apparently create new urban histories, through a concerted effort to address simultaneously main strategic indicators that are decisive for the global performance of an urban agglomeration. The benchmarking information from our analysis may prompt urban policy action. The above results call however, also for some caution. Cities are self-organizing 
organisms that are not entirely makeable. There are issues such a social cohesion, ethnic conflicts, ageing, international migration, natural disasters, human health conditions, and urban governance systems that are difficult to incorporate in a numerical indicator system, even though such factors may decisive for the future fate of a city.

Next, it is also noteworthy that an indicator list - extensive as it may be - will never be entirely complete and entirely fit-for-purpose. For example, the GPCI list is underrepresented in terms of key indicators related to local housing markets, labour markets and quality of the

educational system. A globally successful city can only sustain a high profile, if it is at the same time a 'social polis' with access to many urban amenities by its citizens.

It should be added that there is another element that is difficult to handle, but nevertheless critical for urban competitiveness, viz. the state of urban technology, e.g., in terms of access to and use of advanced technologies, such as biotechnology, nanotechnology, information technology etc. Technological capital seems to be nowadays a sine qua non for modern cities. Clearly, technological capital is not 'manna from heaven', but can be created by dedicated human and policy efforts, for instance, through education and research, in the spirit of the endogenous growth theory (see e.g. Komninos 2002). But technological capital creation is often not in the hands of local policy institutions, but more in the hands of multinational business firms. Seedbed policy for attracting modern technology towards an urban agglomeration is then a key parameter for an internationally competitive position of a city.

Our results are fascinating and intriguing. Long-range dedicated urban development policy does matter. The points of view of the actors allow to look at the performance of cities from different angles. The MAMCA analysis also allows to see the dependencies between the different underlying criteria and the criteria that really make the difference. This allows cities to choose which criteria to work on and by doing so how to increase their attractiveness. A longitudinal study of how the performance changes over time according to stakeholders, might further give information on the dynamics within the city.

Finally, it should be noted that, next to positive forms of policy for the 'new urban world', also effective policies coping with the negative externalities or shadow sides of cities are needed, for instance, regarding ethnic segregation, crime, pollution etc. (see Healey 2007). After all, the city is, by definition, a dynamic and vulnerable spatial entity that needs care for its multiplicity of constituents.

\section{References}

Audretsch, D.B. (1998). Agglomeration and the Location of Innovative Activity. Oxford Review of Economic Policy 14: 18-29 
Begg, I. (1999). Cities and Competitiveness. Urban Studies 36 (5-6_: 795-810

Behzadian, M. Kazemzadh, A. Albadvi, D., Aghdasi, M. 2010, PROMETHEE: A comprehensive literature review on methodologies and application. European Journal of Operational Research, 200, 198-215.

Blanke, B., Smith R., eds. (1999). Cities in Transition. New Challenges, New Responsibilities. London: McMillan

Brans, J.P., Mareschal, B. (1994). The PROMETHEE-GAIA Decision Support System for Multicriteria Investigations. Investigation Operativa 4(2): 107-117

Camagni, R. (1991). Innovation Networks: Spatial Perspectives, London: Belhaven Press

Caragliu, A., Del Bo, C., Nijkamp, P. (2011). Smart Cities in Europe. Journal of Urban Technology 18 (2): 65-82

Diappi, L. (2012). Cities in the Era of the Knowledge Economy. In: R. Cappellin, F. Ferlaino and P. Rizzi (eds.), La Citta nell'Economia della Conoscenza. Milano: FrancoAngeli, pp. 137-146

Farr, D. (2008). Sustainable Urbanism. New York: John Wiley

Florida, R. (2002).The Rise of the Creative Class: and How it's Transforming Work, Leisure, Community and Everyday Life. New York: Basic Books

Hall, P. (2004). Cities of Tomorrow. Oxford: Blackwell

Healey, P. (2007). Urban Complexity and Spatial Strategies. London: Routledge

Ishizaka, A. and A. Labib, (2011), "Review of the main developments in the analytic hierarchy process", Expert Systems with Applications, Volume 38, Issue 11, Pages 14336-14345.

Jacobs, A.J. (2012). The World's Cities: Contrasting Regional, National and Global Perspectives. London: Routledge.

Jacobs, J. (1969). The Economy of Cities. New York: Random House

Komninos, N. (2000). Intelligent Cities. London: SPON Press.

Kourtit, K., Nijkamp, P. (2013). In Praise of Megacities in a Global World. Regional Science Policy and Practice (forthcoming)

Kourtit, K., Nijkamp, P., Suzuki, S. (2012) The Rat Race between World Cities: In Search of Exceptional Places by Means of Super-Efficient Data Development Analysis. Computers, Environment and Urban Systems 38: 67-77

Macharis, C., (2004). The Importance of Stakeholder Analysis in Freight Transport: The MAMCA Methodology. European Transport / Transporti Europei 25/26: 114-126

Macharis, C., Brans, J.P., Mareschal, B. (1998). The GDSS PROMETHEE Procedure - A PROMETHEE-GAIA based Procedure for Group Decision Support. Journal of Decision Systems 7: $283-307$

Macharis, C., Springael, J., De Brucker, K. and Verbeke, A. (2003). "PROMETHEE and AHP: the design of operational synergies in multicriteria-analysis. Strengthening PROMETHEE with ideas of AHP”, European Journal of Operational Research, 153, 2, 307-317.

Macharis, C., De Witte, A., Ampe, J. (2009). The Multi-Actor, Multi-Criteria Analysis Methodology (MAMCA) for the Evaluation of Transport Projects: Theory and Practice. Journal of Advanced Transportation 43(2), 183-202.

Mori Memorial Foundation (2012). Global Power City Index-2012. Tokyo

Munda, G. (2006). Social Multi-Criteria Evaluation for Urban Sustainability Policies. Land Use Policy 32 (1): 86-94

Nam, T., Pardo, T.A. (2011). Conceptualizing Smart City with Dimensions of Technology, People and Institutions. Proceedings of the 12the Annual International Conference on Digital Government Research. MD: College Park, pp. 282-291

Nanetti, R. (2012). Building the Future: Strategic Visions for American Cities and their Relevance for European Cities. In: R. Cappellin, F. Ferlaino and P. Rizzi (eds.), La Citta nell'Economia della Conoscenza. Milano: FrancoAngeli, pp. 147-168

Neal, Z. (2012). The Connected City. New York: Routledge 
Nijkamp, P. (2008). XXQ Factors for Sustainable Urban Development: A Systems Economics View. Romanian Journal of Regional Science 2 (1): 1-34

Nijkamp, P., Rietveld, P., Voogd, H. (1991). Multicriteria Analysis for Physical Planning. Amsterdam: Elsevier.

Rietveld, P. (1980). Multiple Objective Decision Methods and Regional Planning. Amsterdam: NorthHolland Publishers

Saaty T.L. (1982). Decision Making for Leaders. Lifetime Learning Publications. Wadsworth: Belmont

Sassen, S. (1991). The Global City, Princeton NJ: Princeton University Press

Taylor, P.J. (2004). World City Network. London: Routledge

Tranos, E., Nijkamp, P. (2013). The Death of Distance Revisited. Journal of Regional Science (forthcoming)

Winters, J.V. (2010). Why are Smart Cities Growing? Journal of Regional Science 20 (10): 1-18 


\title{
A Multi-Actor Multi-Criteria Analysis of the Performance of Global Cities
}

\author{
Karima Kourtit \\ Dept. of Spatial Economics \\ VU University Amsterdam \\ k.kourtit@vu.nl \\ Cathy Macharis \\ Dept. Transport and Logistics \\ Vrije Universiteit Brussels \\ University of Gotheborg \\ Cathy.Macharis@vub.ac.be
}

\author{
Peter Nijkamp* \\ Dept. of Spatial Economics \\ VU University Amsterdam \\ A. Mickiewicz University Poznan \\ p.nijkamp@vu.nl
}

\begin{abstract}
The strong world-wide urbanisation trend calls for a repositioning of cities, especially the large cities with a global impact. These cities tend to become economic, logistic and political powerhouses and are increasingly involved in a competition on their integral performance. The present paper aims to trace to what extent and why some cities outperform others. Starting from an extensive database on many important characteristics of global cities, this paper offers a multi-criteria methodology for identifying the relative position of various important cities on the basis of distinct assessment criteria. The explicit consideration of the perceptions of important classes of stakeholders on the performance outcomes of the various cities involved allows for a enhanced policy analysis. From a technical assessment perspective, the applied part of the paper employs the MAMCA and PROMETHEE multi-criteria methodology, which have proven their analytical power in various multi-criteria evaluation problems over the past years. The paper concludes with some policy perspectives and lessons.
\end{abstract}

Keywords: Urbanisation, global cities, multi-criteria analysis, performance, stakeholders, MAMCA, PROMETHEE, GAIA

* Tinbergen Institute, The Netherlands 


\section{Aims and Scope}

In our urban century the majority of the people on our planet will live in cities. Urban agglomerations tend to become the ultimate 'destiny' of mankind, with unforeseen challenges for urban research and policy. In the 'new urban world'(see Kourtit and Nijkamp 2013) dominated by connected large cities and urban networks, our society will face serious concerns related to housing, sustainable modes of living, poverty, employment, accessibility, competitiveness, and economic vitality.

World-wide, cities are increasingly seen as engines of economic growth and sustainable development (see Nijkamp 2008). This strategic importance of modern cities - and increasingly, urban agglomerations and metropolitan areas including polynuclear or satellite areas - does not only depend on location advantages (including Marshall-Arrow-Romer (MAR) spatial externalities), but also on two other types of externalities, viz. social capital externalities and connectivity externalities. The first category has been well described by Jacobs (1969) who has introduced the concept of an urban 'melting pot': cities house a multiplicity of people with different cultural, ethnic or language backgrounds which may at times create tensions, but also form the seedbed conditions for innovative and creative behaviour (see e.g. Florida 2002). The second type of externalities is based on economies of connectivity - either physical connectivity through e.g. road or airline networks or virtual connectivity through global information or internet networks (see e.g. Taylor 2004, Tranos and Nijkamp 2013).

The changing scene of cities - from an island position to a nodal position in global networks - has brought about a series of challenges and concerns on cities of the future (see e.g. Blanke and Smith 1999, Hall 2004, Jacobs 2012). According to Nanetti (2012), a strategic vision of future cities calls for the following traits in urban development: territorially-specific, futureoriented, problem-solving, strategically-informed, operationally-translated and politicallycommitted. There is indeed a need for a strategic perspective on 'sustainable urbanism' (see Diappi 2012, Farr 2008, Healey 2007), in which urban gentrification, culture, creative land use, accessibility and ecological sustainability play a central role.

Clearly, the specific favourable facilities and social capital conditions of modern cities tend to induce more creativity and profitability. A spatial concentration of activities, involving spatial and social proximity, increases the opportunities for interaction and knowledge transfer, while the resulting spillover effects reduce the cost of obtaining and processing knowledge. In addition, knowledge workers preferably interact with each other in agglomerated environments so as to reduce interaction costs, while they are more productive in such environments. It is therefore, no wonder that cities become the cradle of new and innovative industries. Innovative firms based on advanced services in the early stages of the product and company life cycle - when dealing with 
a manifold uncertainty - prefer locations where new and specialized knowledge is abundantly available at low costs (see e.g. Audretsch 1998, Camagni 1991). Cities offer in this context an enormously rich potential for a wide array of innovative business opportunities.

Another major megatrend in human settlement patterns is noteworthy in this context, viz. a structural rise in urbanisation in the past centuries. Our world has turned into an urban world, with more than half of the world population living in cities nowadays (see also Kourtit et al. 2012). And the urbanisation degree is still on a rising edge, notably in Latin America, Africa and Asia. This megatrend does not only mean a quantitative change in the share of inhabitants in urban areas in the national territory, but also a qualitative transformation of both a socioeconomic and political nature. Modern network cities have turned into spearheads of (supra)regional and (supra-)national power, not only from a socio-economic perspective (business, innovativeness, jobs, wealth), but also from a geo-political ('cities as global command and control centres'; see Sassen 1991) and a technological perspective.

To meet a wide array of future challenges and opportunities, urban agglomerations and their business operations have to be smart and resilient. And therefore, over the years modern global cities have dramatically changed the way of managing dynamics in urban development in order to become and remain an attractive environment for various stakeholders, for example, in attracting and retaining firms or tourists and in recruiting talented people in a vibrant urban environment. To that end, appropriate support systems for a creative business environment need to be developed, and more resources for sustainable growth need to be provided. Repositioning of modern global cities calls for a solid evidence-based benchmarking analysis (see Begg 1999).

A major question is now: which are the critical parameters that may serve as policy handles for a successful urban development? The road towards economic growth, social inclusion and environmental sustainability of a city is not easy to achieve. In recent years, the concept of a 'smart city' has gained increasing popularity and has prompted a great deal of policy attention and research interest (see e.g. Caragliu et al. 2011, Winters 2010). In a recent paper by Nam and Pardo (2011), a list of smart cities all over the world can be found, while also various definitions of a smart city - and conceptual relatives of a smart city (e.g. digital city, learning city) - are recorded and described. A main issue in analyzing smart cities - or related concepts - is: what makes a city smarter than another city?

The above question has prompted much empirical research on ranking of cities in our world, such as the Economist Intelligence Unit addressing liveability of cities. Obvious caveats in comparing the performance of different cities are: differences in city size, the number of and type of indicators used, the sample of cities chosen, the goal of the interurban comparison etc. In the present study we will compare the performance of various world cities based on a set of extensive and carefully collected indicators. In a relatively short time, this set of indicators - 
known as the GPCI (Global Power City Index), provided and updated on an annual basis by the Mori Memorial Foundation in Japan (2012) - has become a unique source of scientific research on cities world-wide (see e.g. Kourtit et al. 2012).

Our study aims now to offer an in-depth analysis of the GPCI database on 40 world cities (see Section 2). It offers a comparative benchmark assessment of these cities by investigating their detailed performance indicators on the basis of a recently developed multi-criteria model coined MAMCA (see Section 3). This methodology enables the explicit consideration of the perceptions and priorities of various distinct classes of stakeholders. The results of this experiment are presented and interpreted in Section 4, while Section 5 offers some policy perspectives and lessons.

\section{Description of the Database}

Cities are engines of economic power but also nodes in global networks. They need each other, but are also each other's competitors. The combination of internal strength and external orientation determines the growth potential and economic position of cities (see Neal 2012). Cities operate in an international playing field and, hence, their socio-economic performance may show much variation. The question is then: why do some cities outperform others? This idea formed the basis of the creation of the above-mentioned GPCI database. This database contains extensive information - in numerical form - of many world cities which are evaluated and ranked according to their 'magnetism', e.g. their competitive power to attract creative people and business enterprises from all over the world. This open access database is carefully validated through field visits and in-depth reports. It contains a wealth of multi-annual data on major critical indicators - and a very detailed list of sub-indicators - for economic strength of the relevant cities contained in the database. At present, this data system has accurate information on 40 world cities ranging from New York to Istanbul, and from Tokyo to Geneva. In addition, a similar database has been created for 9 Japanese cities that were not included in the overall data bases, for instance, Sapporo, Yokohama, Nagoya or Kobe. This extensive GPCI database offers also the possibility for benchmarking of each individual city, in terms of strength and weakness regarding each individual performance indicator.

Thus, the GPCI aims to offer systematic and comparative information on the comprehensive economic position of major cities in the world, and it does so by focussing on a wide variety of functions performed by the cities under consideration. For each individual city, 6 main classes of functions were carefully mapped out and numerically assessed, viz. economy, research and development, cultural interaction, liveability, environment and accessibility. In addition, the importance of these indicators was carefully assessed by 5 distinct groups of 
stakeholders, viz. managers, researchers, artists, visitors and residents. The summary results from the 2012 GPCI rankings are contained in Figure 1.

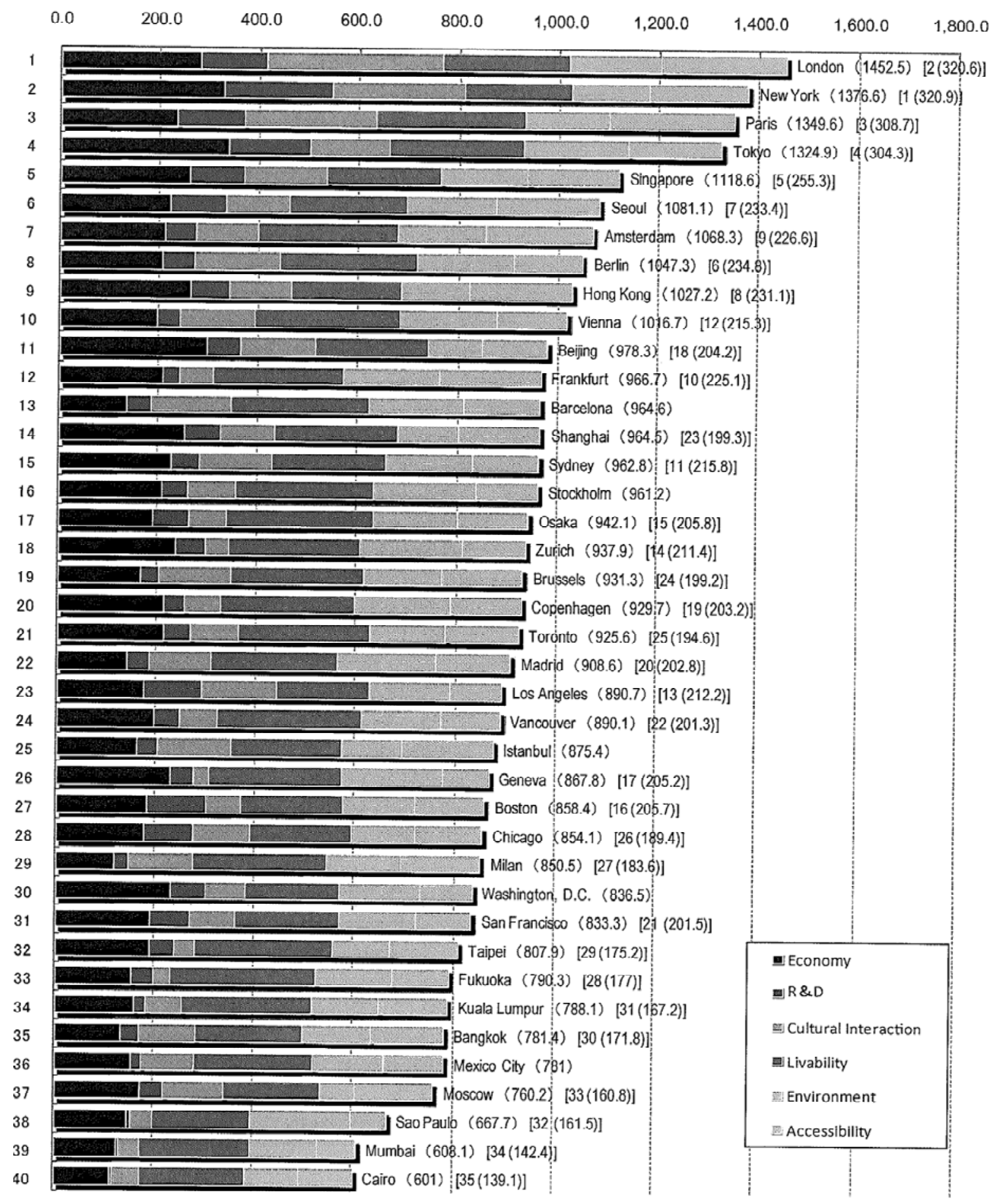

*Numbers in [ ] are scores/ranks from the GPCl-2011

Figure 1. Comprehensive scores and ranking of 40 global cities by 6 functions

Source: Mori Memorial Foundation (2012) 


\section{Results of the MAMCA Model}

Our study has tried to identify the potentially most powerful global city - measured in terms of 6 main criteria and a vast set of subcriteria - by applying an appropriate multi-criteria model, coined MAMCA. MAMCA is a member of the family of multi-criteria analysis methods which have gained much popularity over the past decades. It has also often been applied in urban and regional evaluation methods (see, e.g. Nijkamp et al. 1991, Munda 2006). The MAMCA (in full, Multi-Actor, Multi-Criteria Analysis) model allows not only to perform a multi-criteria analysis on the basis of standard information on alternatives and choice criteria, but also to include preference elicitation through an explicit involvement of relevant stakeholders (Macharis 2004, Macharis et al. 2009). MAMCA is a methodology, a stepwise structured approach to analyse the opinions of these stakeholders. The data from the GPCI system are very suitable for the MAMCA approach, as they include the criteria and the underlying indicators for each actor together with the importance these actors are attaching to a specific criterion. Within our evaluation methodology, different multi-criteria analysis (MCA) techniques can be used. In this paper we show the possibilities of two frequently used and related MCA methods, namely the Analytical Hierarchy Analysis (AHP) method (or Saaty method) and the PROMETHEE method in order to analyse the GPCI data (Macharis et al., 2003). We have chosen these two methods as they belong to two different MCA schools, namely the American (AHP) and the European school (PROMETHEE). Both methods have found extensive application in the MCA literature (see Behzadian et al. (2010) for an overview of applications with PROMETHEE and Ishizaka and Labib, (2011) for AHP).

We will first illustrate the use of MAMCA by addressing the relative performance profiles of 8, rather arbitrarily chosen cities from our GPCI set. By the use of expert choice software (in distributive mode), supporting the use of the Analytical Hierarchy Process method developed by Saaty (1982), the data of GPCI (2012) for the cities of London, Paris, New York, Tokyo, Singapore, Amsterdam, Berlin and Brussels were selected, taking into account the observed preference intensity of various classes of stakeholders regarding these cities.

The meaning of the MAMCA analysis will be clarified by means of Figure 2, in which the viewpoint for the category "visitor" is shown. On the horizontal axis the criteria of this class of actors are shown. The height of the bar shows the weight the class of visitors is attaching to the respective criterion concerned. The left axis gives the scales of these weights. On the right axis, the scores of the cities on the criteria provided by the class of visitors can be seen. The overall ranking is also shown. This overall ranking is a weighted sum of the specific score on each of the criteria, while taking the weights into account. London, Paris and New York are clearly ranked 
on a top position for this actor. However, all cities have clear positive performance outcomes, but amongst these also elements in which they can improve their performance. The dining possibilities in Tokyo really stand out, for example, while its mobility (in particular, accessibility) leaves room for improvement. What is also becoming obvious from this figure is that some criteria are clearly differentiating between the cities, like dining or cultural interaction, while other criteria like safety are quite similar for all cities.

Next, when we bring the points of view of all classes of stakeholders regarding these 8 cities together in a multi-actor profile (as shown in Figure 3), we can again observe some very interesting elements. In this graph the different categories of actors are shown on the horizontal axis. If all actors receive an equal weight, then Paris, London and New York all end up at a top position, but one can clearly see also differences in achievement. Researchers appear to prefer New York, while artists would prefer Paris. Tokyo is in the middle, followed by a lower group with Berlin, Singapore, Amsterdam and Brussels. Berlin, Amsterdam and Brussels appear to show the same pattern with always the same ranking, but Singapore is clearly very attractive for doing business, but clearly, much less attractive for the class of artists.

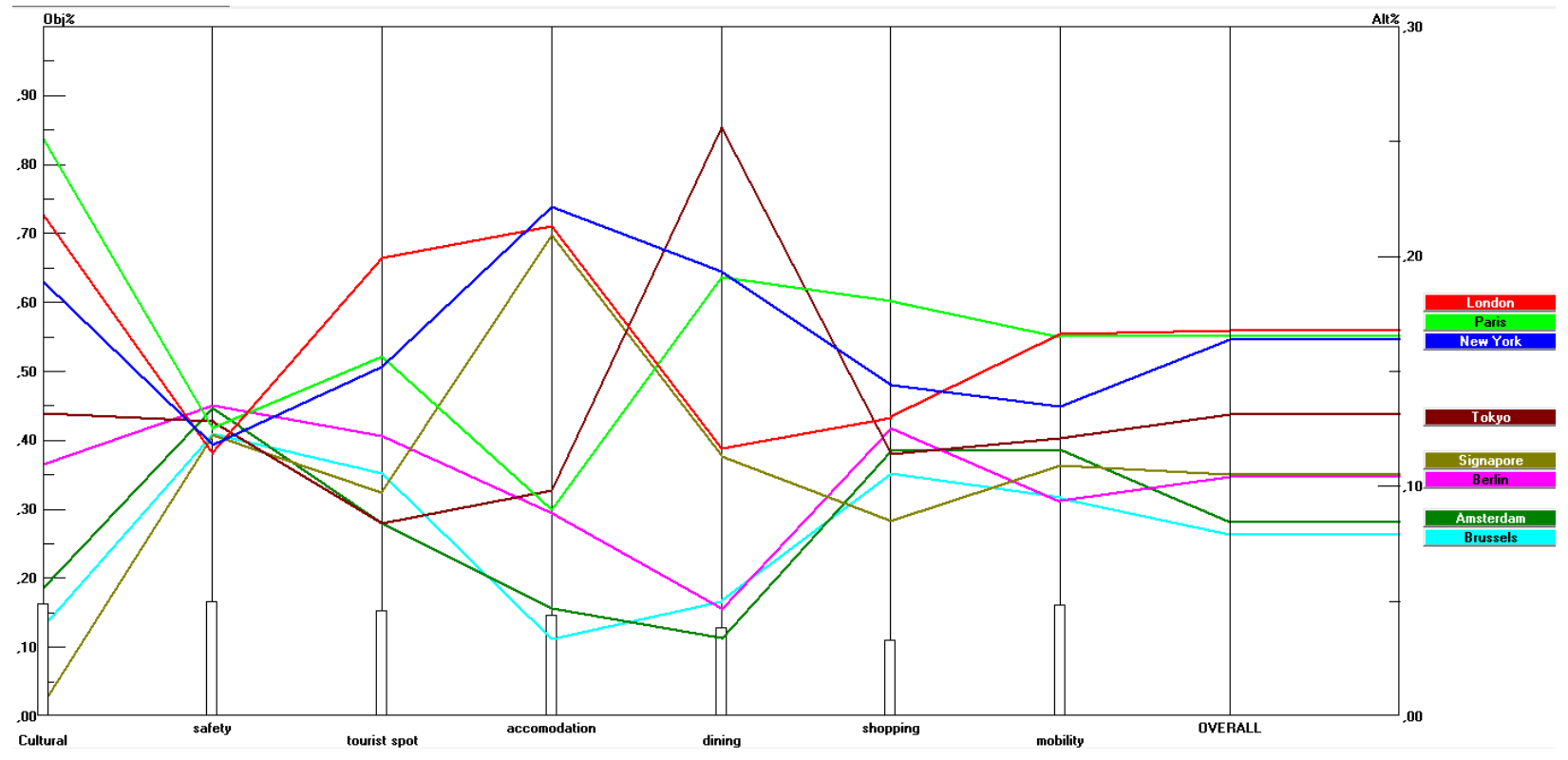

Figure 2. MAMCA results for 8 world cities from the perspective of the class of 'visitors' 


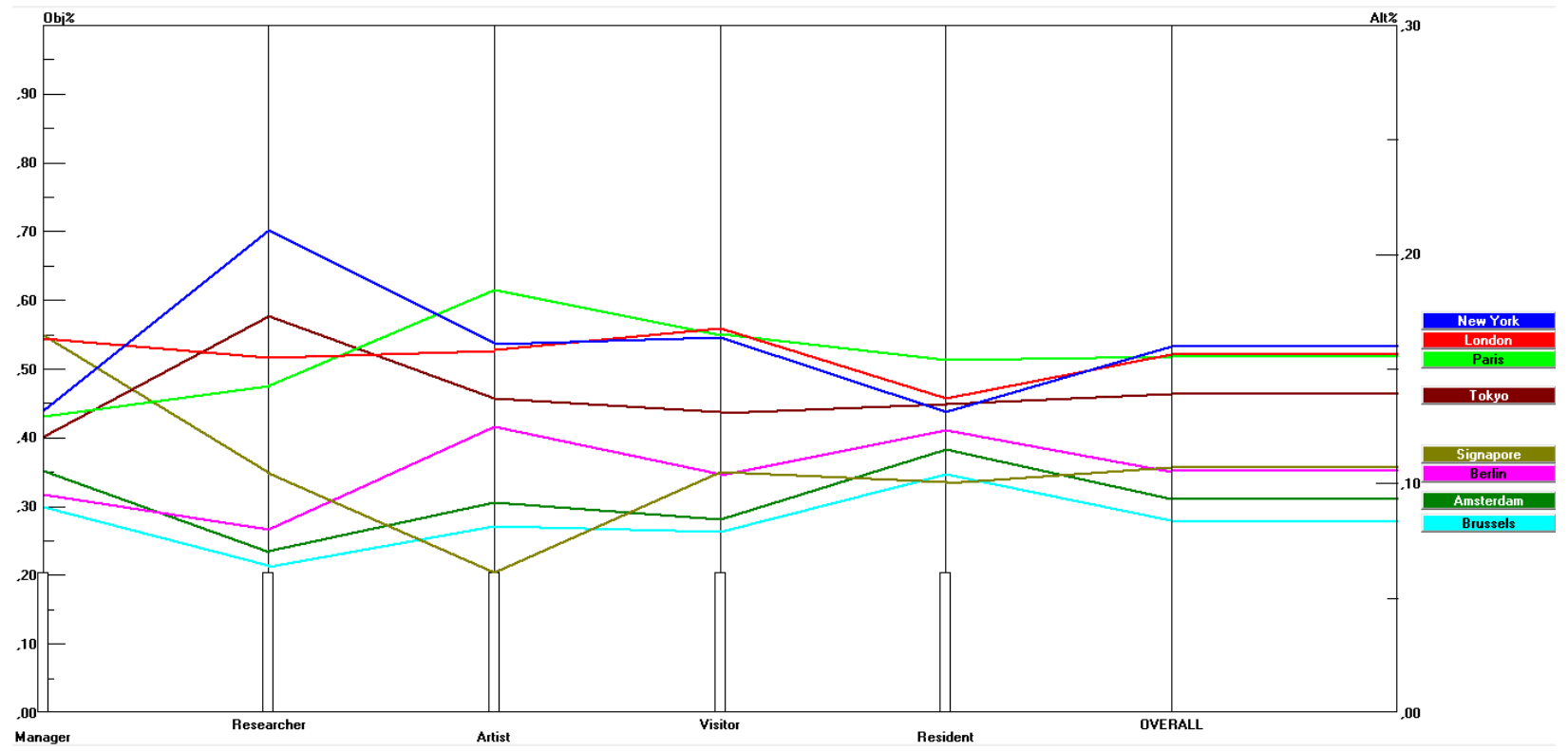

Figure 3. MAMCA results for 8 world cities from the perspective of all classes of stakeholders

The advantage of the MAMCA model is that it has the potential to offer the strengthweakness profiles of various choice alternatives, seen from the perspective of both different judgment criteria and different groups of stakeholders. Clearly, if the number of choice options is very large (like in our case, 40 cities), it becomes somewhat cumbersome to present all outcomes in one graph. But any specific subset of interesting choice alternatives can of course be taken and mapped out in the respective graphs. In the remaining part of this section we will offer the results from various other interesting combinations of cities in order to illustrate the power of the MAMCA approach.

It goes without saying that several sensitivity analyses are also possible with the MAMCA model, for instance, by adding all cities from the GPCI database, by zooming in on size classes, on continents, specific stakeholders or specific criteria. Also the stakeholders can be given different weights, for example give more weight to the opinions of the residents compared to the artists. So a complete sensitivity analysis is possible. If we make a selection of the top-10 most efficient cities from the GPCI database - with a selection made on the basis of a recently undertaken DEA-analysis; for details, see Kourtit et al. (2012), - the multi-actor analysis shows that for each class of actors New York and Tokyo are really on top of and far above the others (see Figure 4). For the remaining 8 cities we see that they exhibit different profiles. For example, Hong Kong appears to have a very high ranking for managers, but less so for artists. 


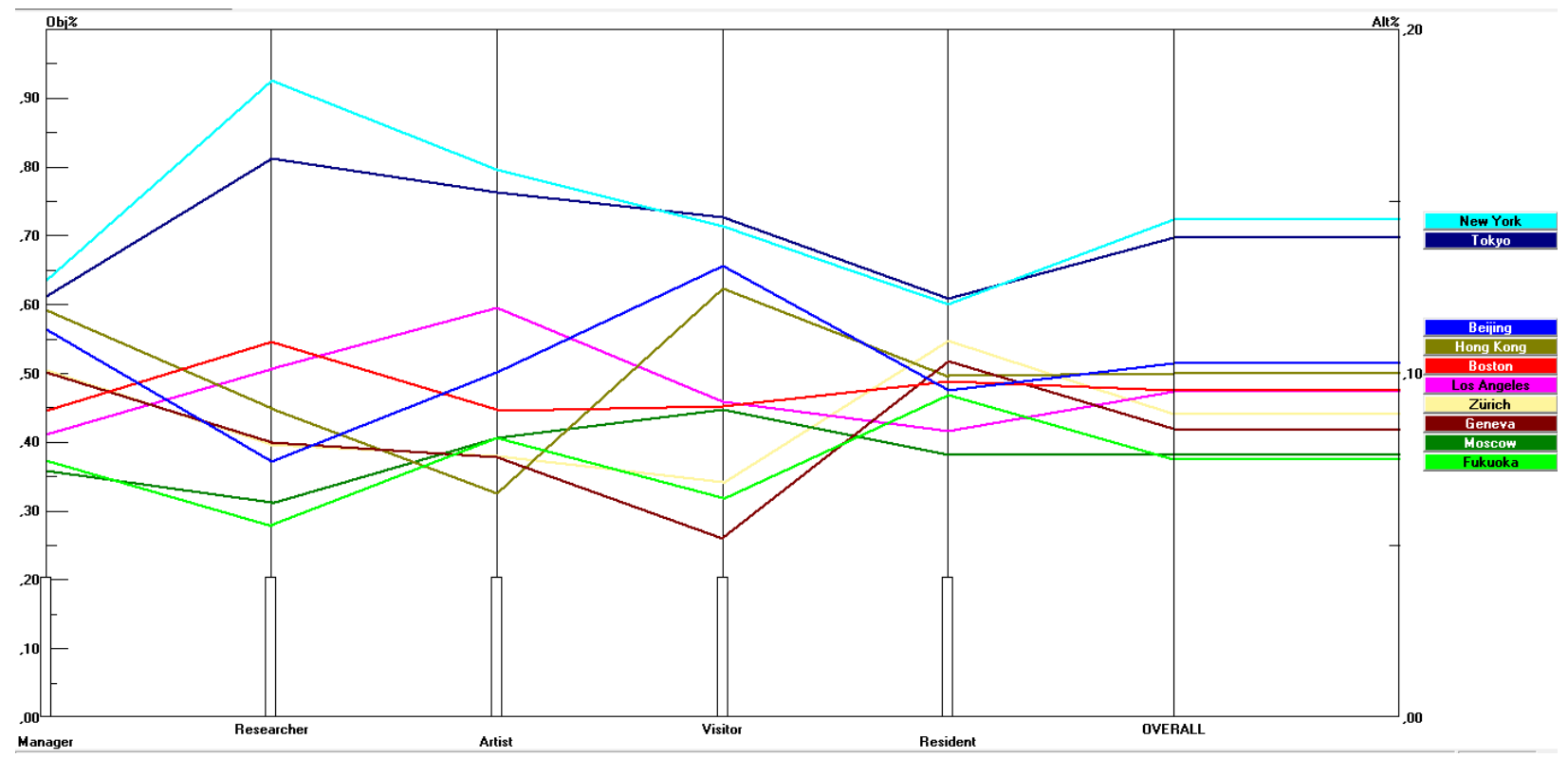

Figure 4. MAMCA results for the top-10 most efficient world cities from the GPCI database, from the perspective of all classes of stakeholders

It may be added that also for the class of top-10 GPCI cities the strength-weakness profile for a given class of stakeholders, for example, the class of visitors, can again be mapped out, so that a more detailed view on the positive and negative aspects of a city for that specific actor can be provided (see Figure 5). This figure also shows which criteria might be really differentiators. The more the scores are dispersed, the more this criterion is differentiating among distinct judgement criteria, for example, high class accommodation; on the other hand, mobility (including accessibility), a criterion which receives a large weight by the class of visitors, appears to discriminate less in the different cities considered here. Furthermore, safety is certainly a criterion for which the cities which score high on most of the other criteria, are not performing so well. 


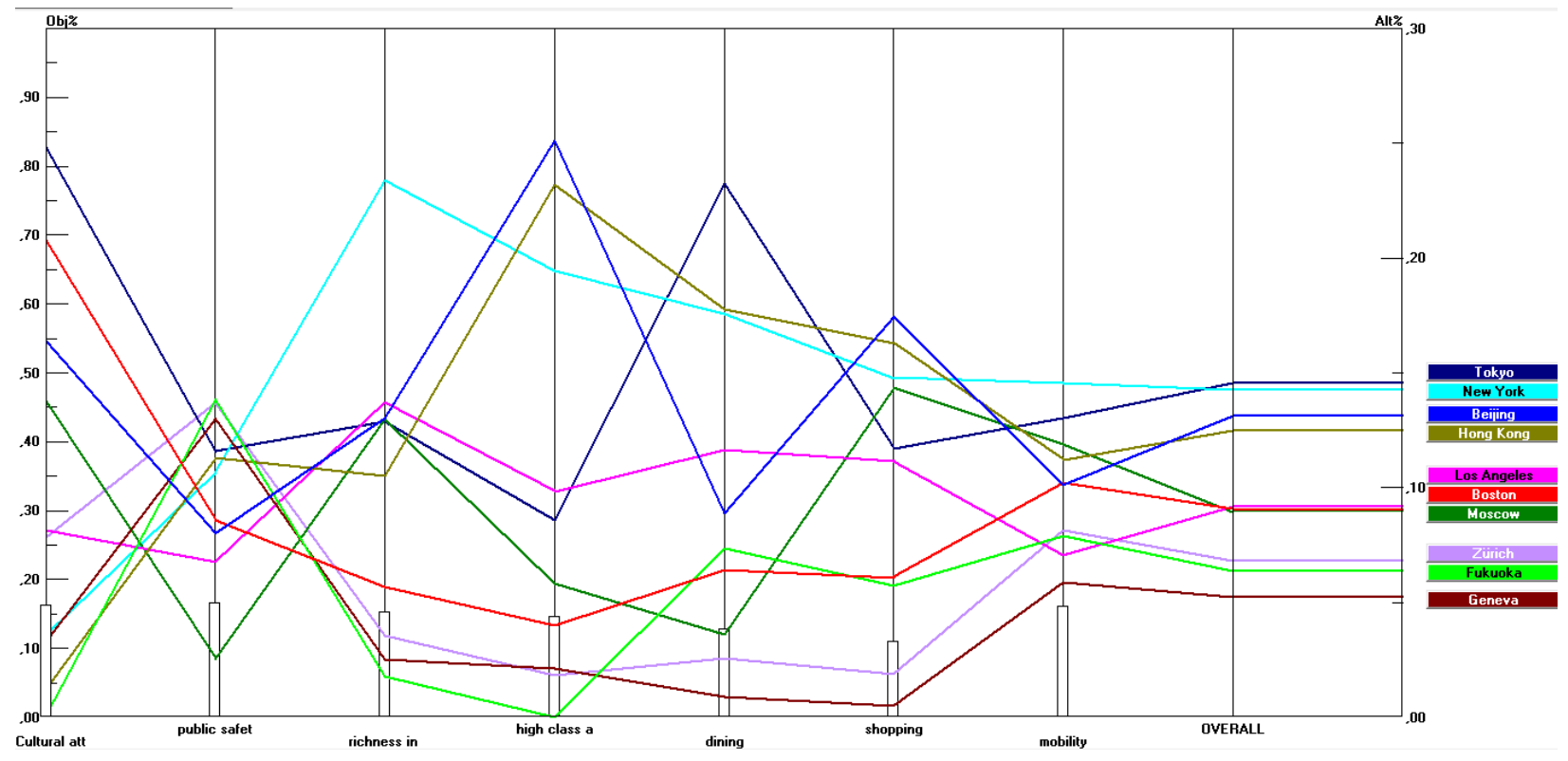

Figure 5. MAMCA results for the top-10 most efficient world cities from the perspective of the class of 'visitors'

For the 10 lowest scoring cities - in terms of efficient performance - in the DEA analysis executed by Kourtit et al. (2012), a similar analysis is next executed, where Paris acts essentially as a benchmark for the others. We present here (see Figure 6) only the overall results, seen from the perspective of all classes of stakeholders. This figure is similar in contents to the above presented Figure 4. It appears that Paris is clearly standing out in this class of lower ranked cities. Clearly, although it is not an efficient city, it has several advantages for different actors.

The clearly differentiating nature of the MAMCA model results can be shown by focussing the attention, for example, on the class of 'artists'. In this respect, Paris takes the clear lead in its importance of a cultural and artistic centre, far above all other cities in this subset of GPCI cities (see Figure 7). 


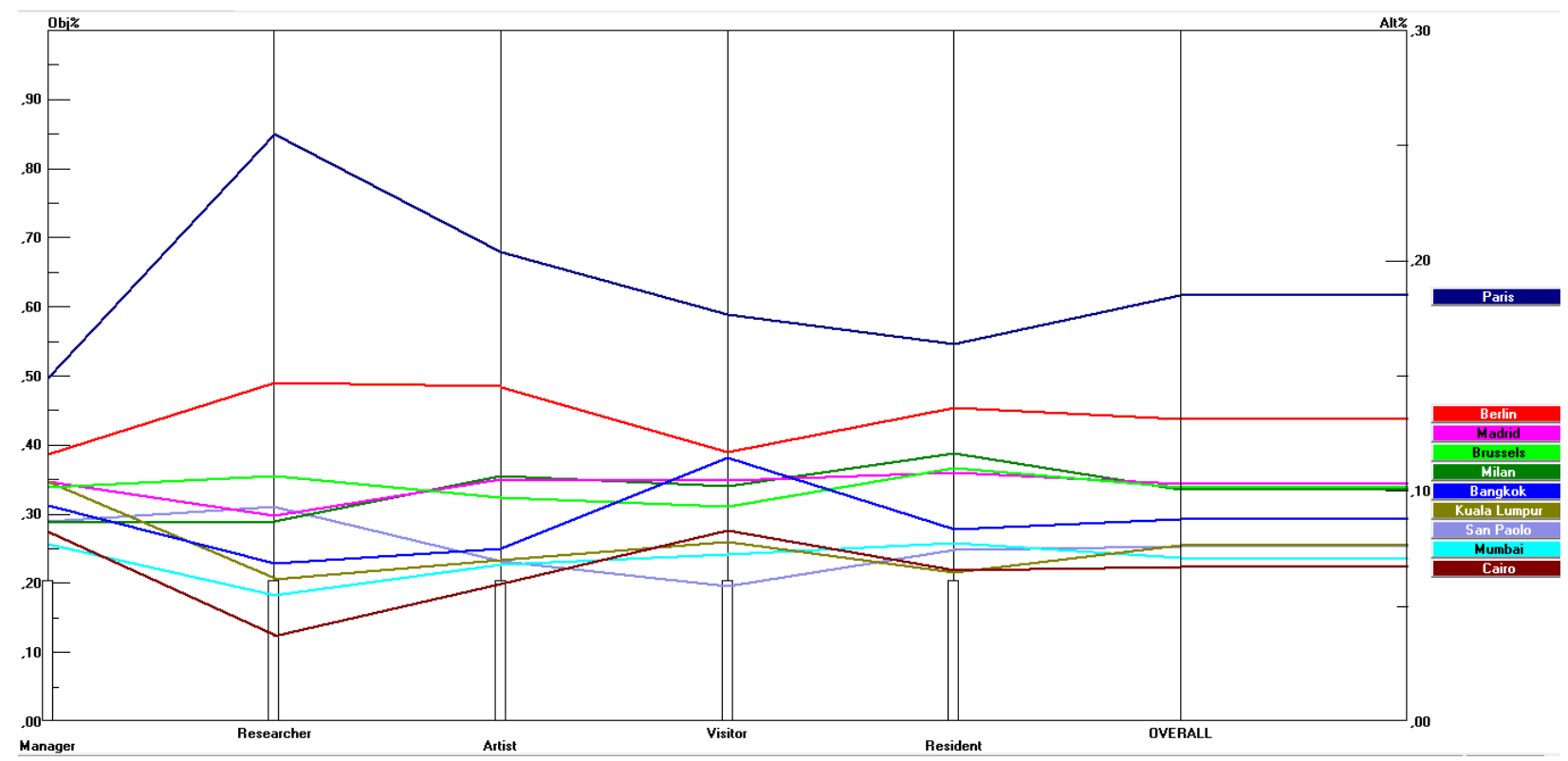

Figure 6. MAMCA results for the bottom-10 world cities - in terms of efficiency - from the perspective of all classes of stakeholders (with Paris as a benchmark)

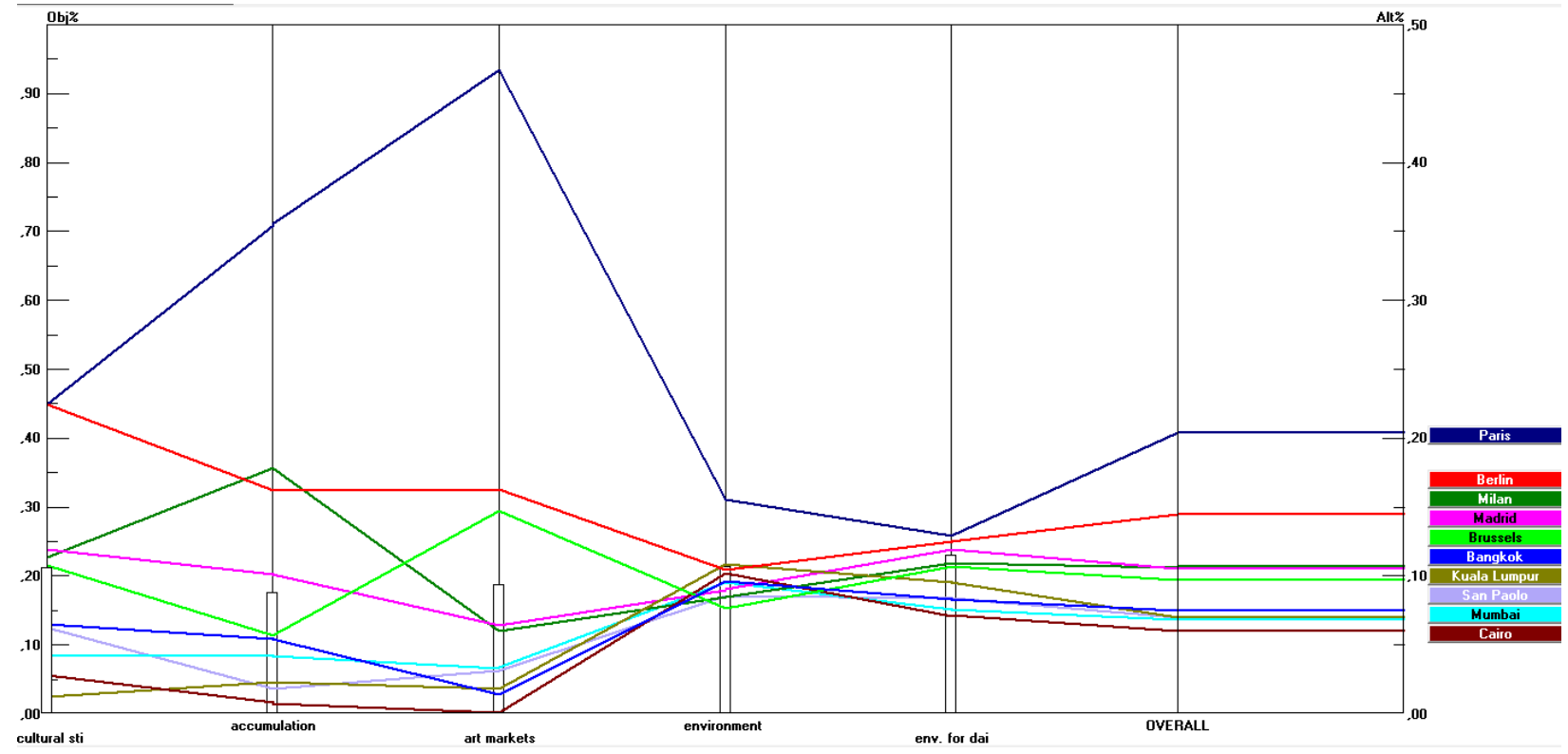

Figure 7. MAMCA results for the bottom-10 world cities - in terms of efficiency - from the perspective of the class of 'artists' (with Paris as a benchmark)

The MAMCA model offers clearly a broad perspective on the factors determining the perceived performance of world cities. An often heard complaint in the use of multi-criteria analysis (MCA) for evaluating choice alternatives is that the results may be sensitive to the MCA method chosen. To clarify the scope of such a multi-criteria method, we have therefore used 
another MCA method, the so-called PROMETHEE approach (see for details Brans and Mareschal 1994) and its extension towards group decisions (see for details Macharis et al. 1998).

This method - and in particular the so-called GAIA variant - is able to link the total performance evaluation of relevant alternatives to the various classes of stakeholders. In using the PROMETHEE software called D-Sight, different analysis methods can be used. We will present here the results of a specific technique, the GAIA method. The GAIA (Geometrical Analysis for Interactive Aid) plane is a two-dimensional visual representation of a decision problem in which the alternatives and their contribution to the various criteria are simultaneously displayed. In a multi-actor setting, GAIA will show the points of view of the different actors in the plane. Additionally, a decision stick can be used to further investigate the sensitivity of the results as a function of weight changes (see Brans and Mareschal 1994).

The GAIA method plots the different cities in a two-dimensional space by using a principal component analysis. Each axis represents the point of view of each of the actors concerned, while the decision axis (the red axis) shows the cities which overall have the highest score. For the sake of illustration, in the next graph, a comparison is made between the EU cities (the yellow ones) and the non-EU cities (the purple ones) within the top-10 cities of the GPCI database (see Figure 8). 


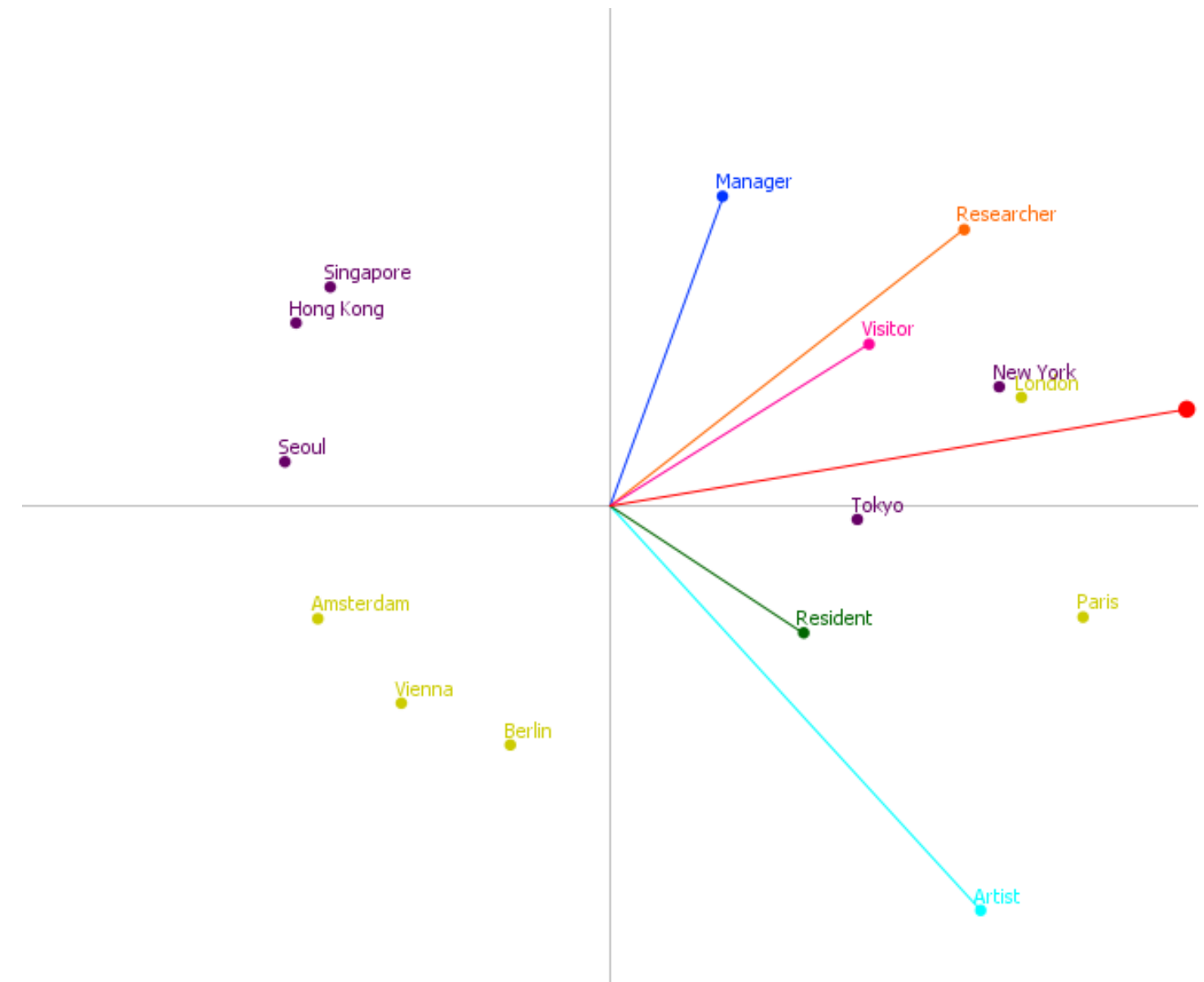

Figure 8. GAIA plane with topological positions for the selected EU and non-EU top-10 cities

It is interesting to see that the actor axes in Figure 8 are pointing to the right, meaning that the perception of stakeholders on the performance of the cities is not completely opposite. The points of view appear to deviate most between artists and managers. The decision axis is pointing in the direction of New York, London and Tokyo. Most of the European cities are situated at the lower level, showing that these are interesting places for staying there as residents or artists.

Clearly, such types of analysis can be carried out for different cities and perspectives in our database. A similar analysis can, for instance, be done with a distinction between mega-cities versus non-megacities, OECD countries versus non-OECD countries, and so forth. All such experiments allow to identify what the contribution is of each of these points of view to the overall score.

Such ranking analyses can be undertaken for various subsets, such as the top-10 cities in our database, discussed above (see Figure 9). Then, it turns out that Paris, London, New York and Tokyo are clearly ranked in the top. The contribution of each of the actors is equally divided. Singapore has quite an unique profile. It scores very good for managers, but not that good for artists. In this graph it is clear that the points of view of the visitors and researchers are very 
close to each other. If we look at the scores on the criteria of these two actors, we see indeed that there is quite a high correlation between them.

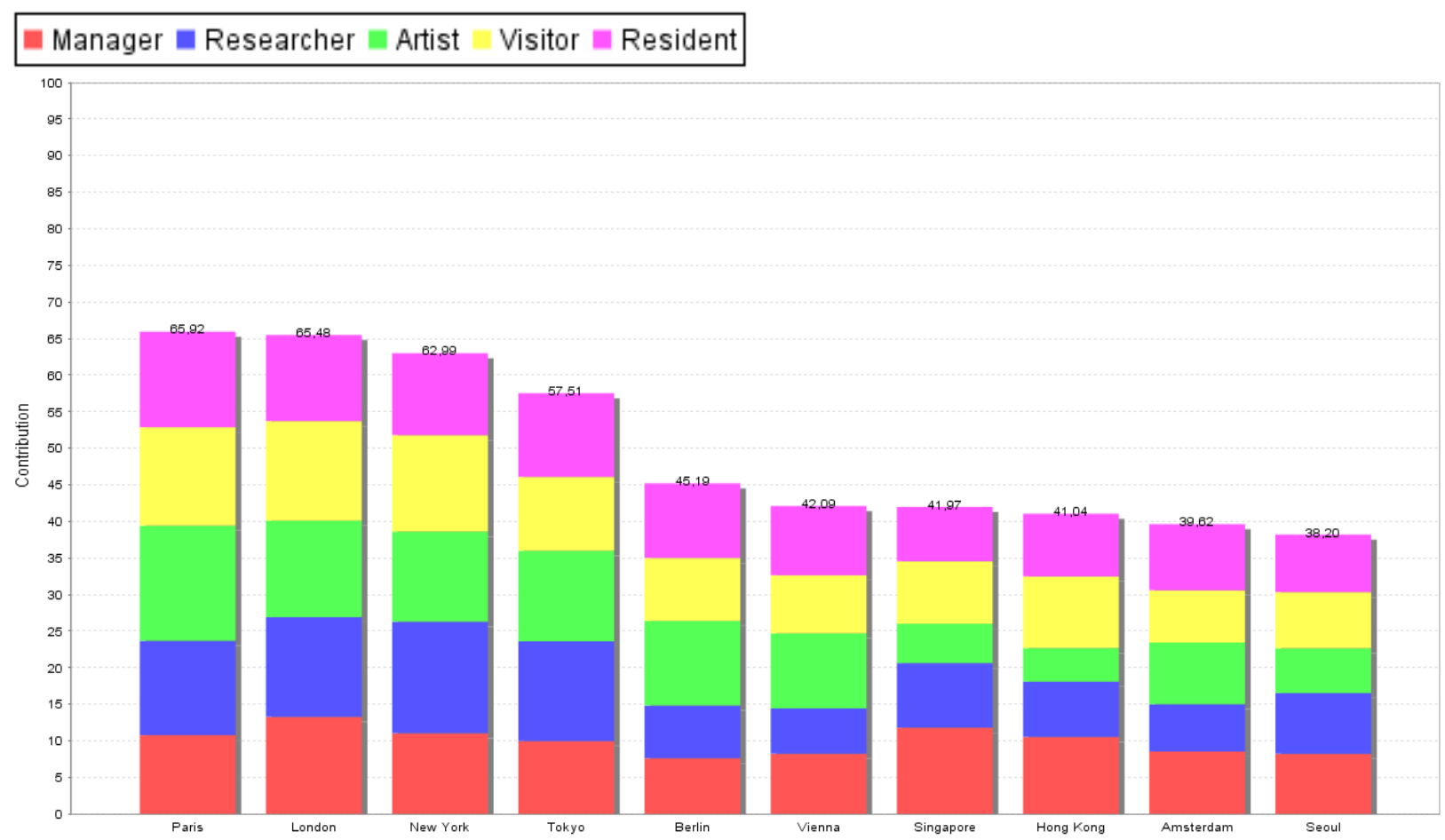

Figure 9. Overall ranks of the top-10 cities on the basis of the PROMETHEE method

In addition to achieving the rankings of cities based on a combined multi-stakeholdermulti-criteria approach, it is also possible to identify the closeness between clusters of cities through an appropriate cluster algorithm based on an A-versus B-analysis. In Figure 10 the two classes of actors 'visitors' (A) and 'researchers' (B) are compared to each other. The higher the correlation between the two criteria the more the cities would be located near the diagonal line. We see that for these two classes of actors, the correlation is not that high, meaning that these actors have quite differentiated and independent objectives/criteria. 


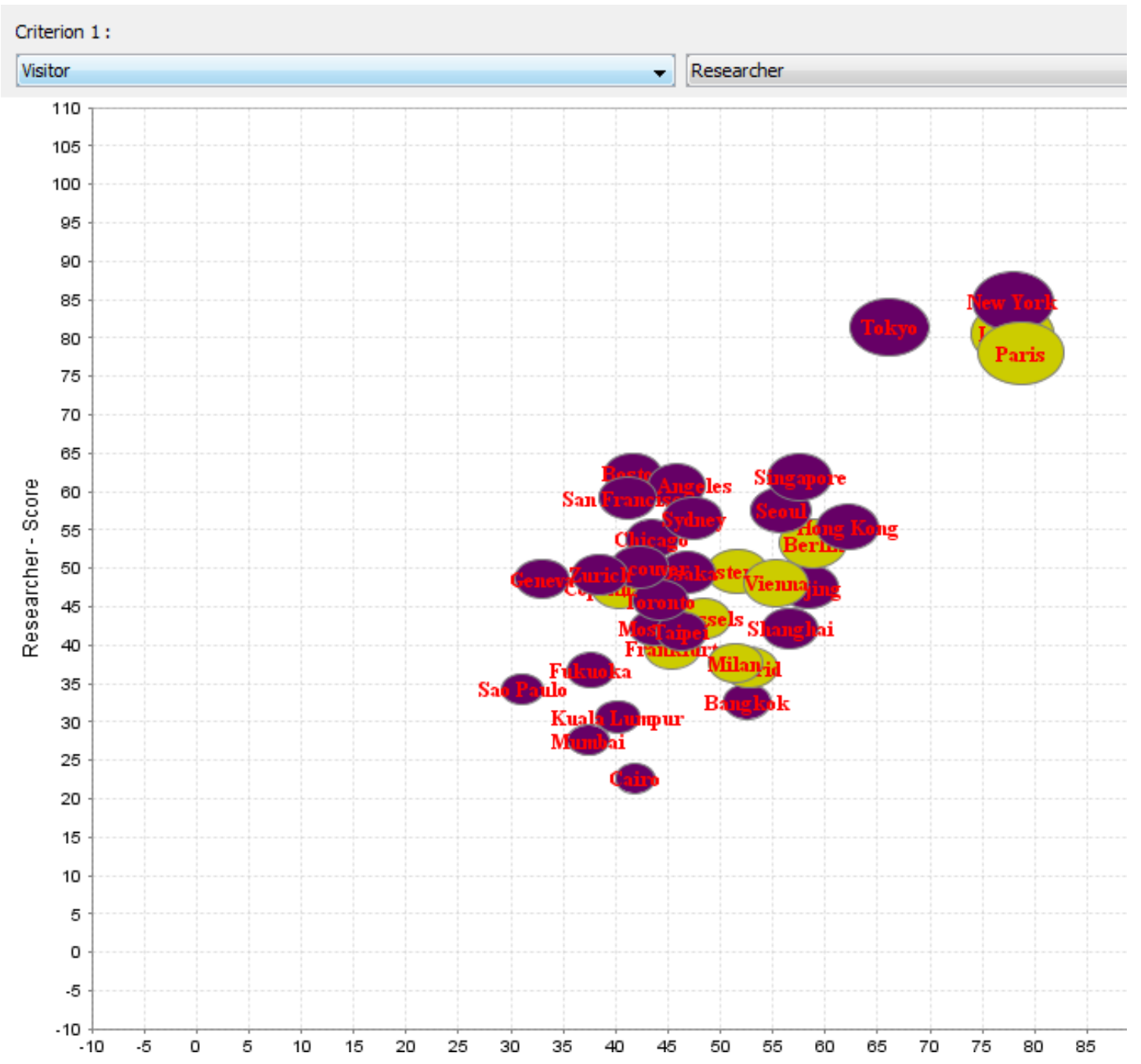

Figure 10. A (visitor)- versus B (researcher)- analysis with all cities (green: EU countries, purple: non-EU countries).

Comparisons of individual criteria between actors are also possible. An obvious but illustrative example in our modeling approach is a combined analysis of two attraction factors, viz. the concentration of artists (a social network criterion for artists) and cultural attractiveness of a city (an attractiveness criterion for visitors). Figure 11 shows that this correlation is indeed very high, as the cities are located near the diagonal. This kind of analysis can show the most prominent and interesting interactions between the criteria at hand. So if a city is addressing one of them, this will indirectly also lead to an interesting increase of the scores for another related actor. 


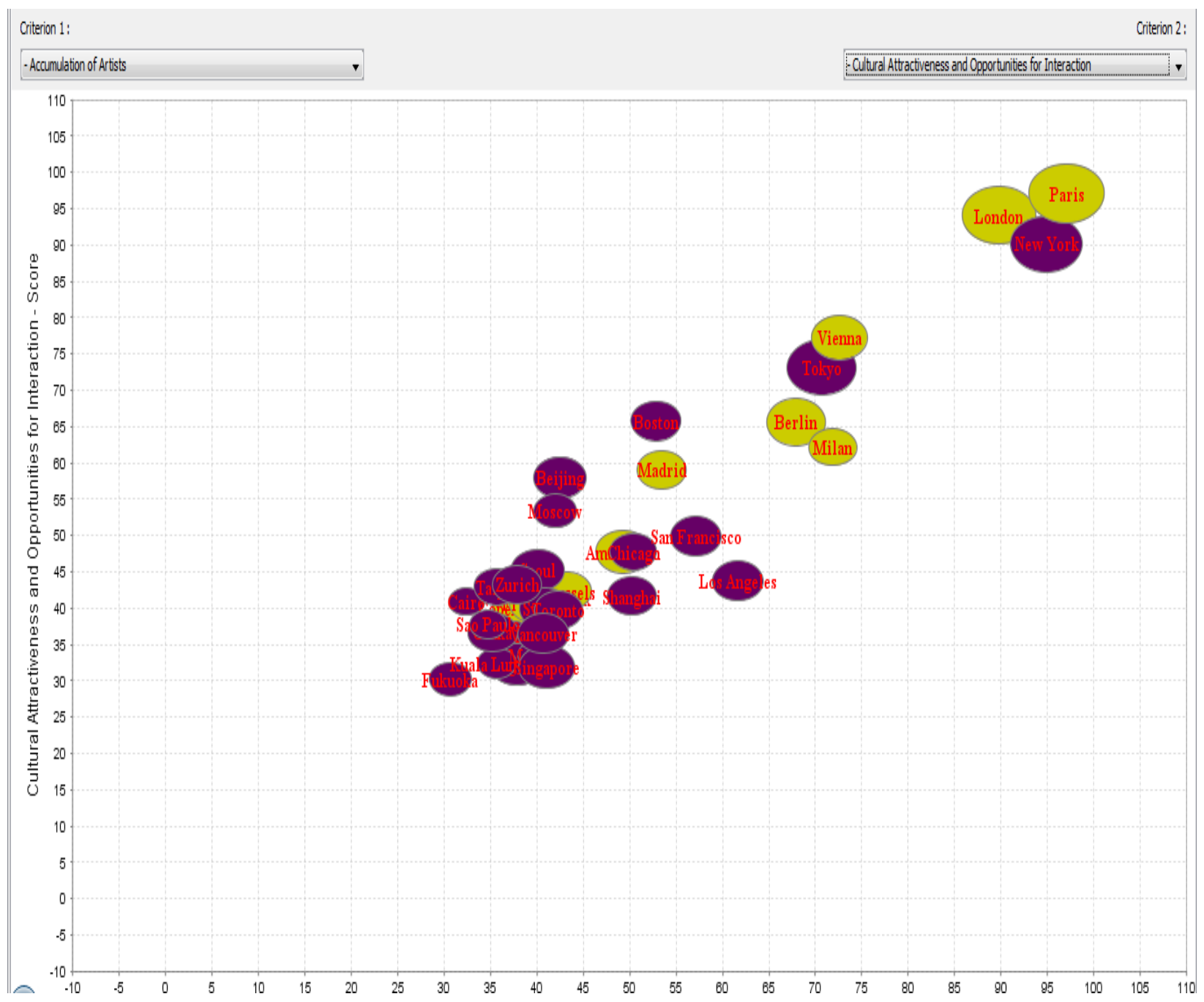

Figure 11. A (concentration of artists)- versus B (cultural attractiveness)- analysis for all cities

If we compare the PROMETHEE method with the AHP method for a MAMCA application to the GPCI data, we may conclude that they are quite complementary. In Figure 12, we show the analysis for the same 7 randomly selected cities as considered above for AHP. The GAIA plane appears to show better the points of view of the different actors and how the cities can be clustered according to these points of view. For example, New York, London, Tokyo and Paris are situated on the positive side of the plane (in the direction of the decision stick). Paris scores better for residents and artists, while New York and London score higher for researchers and managers. Also for the cities that have a lower score, important findings can be extracted from these visual presentations. For example, Singapore scores good for managers, but less so for artists, a conclusion we have also drawn from the AHP analysis. 


\section{Policy Lessons}

The above analysis has brought to light important findings on the relative position of major cities in our world. Apparently, if we look at the rankings of all cities for each individual main indicator, there is no unambiguous winner in all dimensions. In multi-objective programming terms: there is no single super-efficient solution in the set of alternatives (see Rietveld 1980). But there are several cities which score higher on all indicators than others. These cities may be called dominant cities, as they outperform all the others. Clearly, the results may change, if different groups of stakeholders attach different priorities (weights) to the various main indicators.

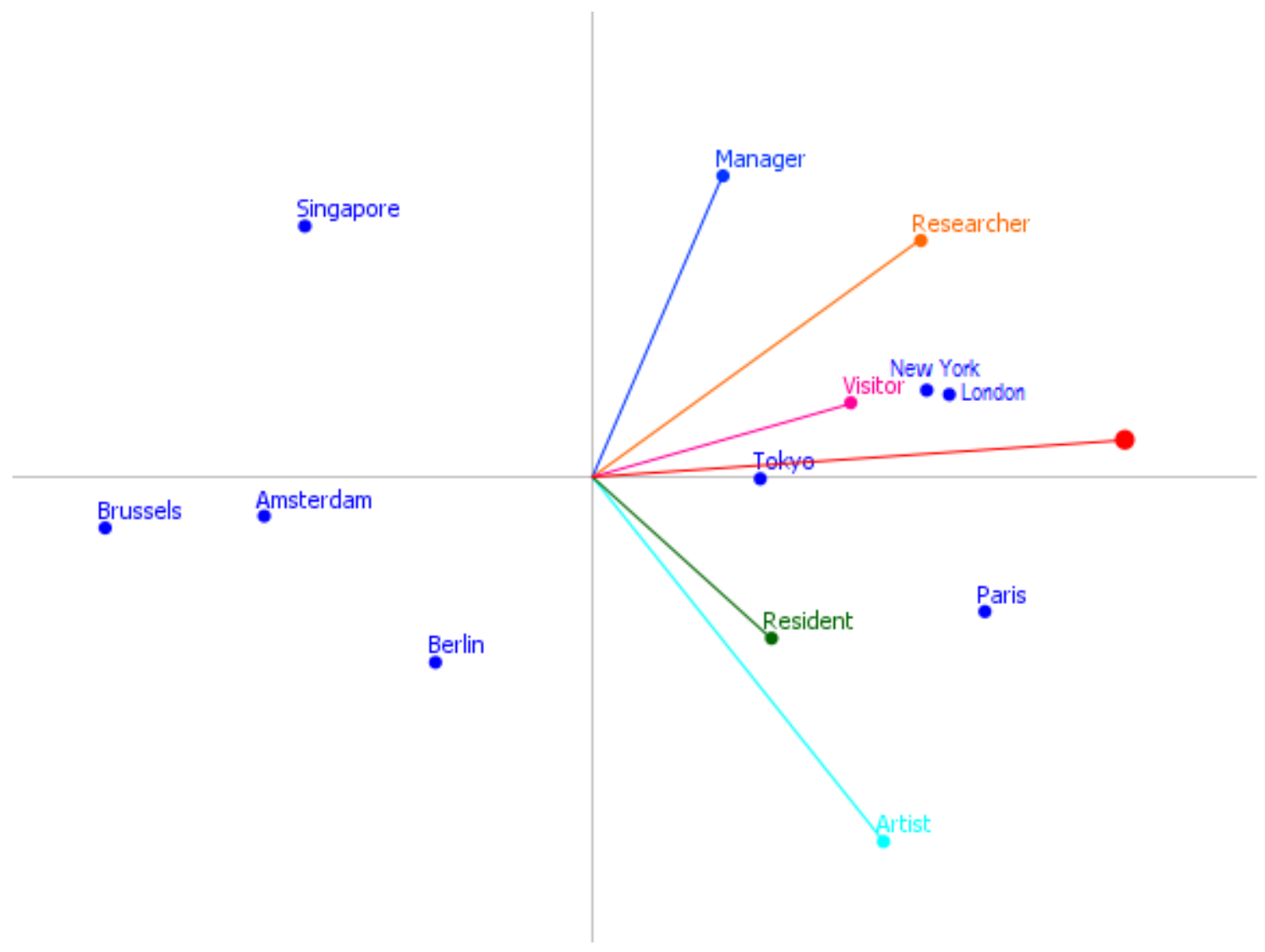

Figure 12. GAIA plane for 7 world cities, as compared to Figures 2 and 3

Cities can apparently create new urban histories, through a concerted effort to address simultaneously main strategic indicators that are decisive for the global performance of an urban agglomeration. The benchmarking information from our analysis may prompt urban policy action. The above results call however, also for some caution. Cities are self-organizing 
organisms that are not entirely makeable. There are issues such a social cohesion, ethnic conflicts, ageing, international migration, natural disasters, human health conditions, and urban governance systems that are difficult to incorporate in a numerical indicator system, even though such factors may decisive for the future fate of a city.

Next, it is also noteworthy that an indicator list - extensive as it may be - will never be entirely complete and entirely fit-for-purpose. For example, the GPCI list is underrepresented in terms of key indicators related to local housing markets, labour markets and quality of the

educational system. A globally successful city can only sustain a high profile, if it is at the same time a 'social polis' with access to many urban amenities by its citizens.

It should be added that there is another element that is difficult to handle, but nevertheless critical for urban competitiveness, viz. the state of urban technology, e.g., in terms of access to and use of advanced technologies, such as biotechnology, nanotechnology, information technology etc. Technological capital seems to be nowadays a sine qua non for modern cities. Clearly, technological capital is not 'manna from heaven', but can be created by dedicated human and policy efforts, for instance, through education and research, in the spirit of the endogenous growth theory (see e.g. Komninos 2002). But technological capital creation is often not in the hands of local policy institutions, but more in the hands of multinational business firms. Seedbed policy for attracting modern technology towards an urban agglomeration is then a key parameter for an internationally competitive position of a city.

Our results are fascinating and intriguing. Long-range dedicated urban development policy does matter. The points of view of the actors allow to look at the performance of cities from different angles. The MAMCA analysis also allows to see the dependencies between the different underlying criteria and the criteria that really make the difference. This allows cities to choose which criteria to work on and by doing so how to increase their attractiveness. A longitudinal study of how the performance changes over time according to stakeholders, might further give information on the dynamics within the city.

Finally, it should be noted that, next to positive forms of policy for the 'new urban world', also effective policies coping with the negative externalities or shadow sides of cities are needed, for instance, regarding ethnic segregation, crime, pollution etc. (see Healey 2007). After all, the city is, by definition, a dynamic and vulnerable spatial entity that needs care for its multiplicity of constituents.

\section{References}

Audretsch, D.B. (1998). Agglomeration and the Location of Innovative Activity. Oxford Review of Economic Policy 14: 18-29 
Begg, I. (1999). Cities and Competitiveness. Urban Studies 36 (5-6_: 795-810

Behzadian, M. Kazemzadh, A. Albadvi, D., Aghdasi, M. 2010, PROMETHEE: A comprehensive literature review on methodologies and application. European Journal of Operational Research, 200, 198-215.

Blanke, B., Smith R., eds. (1999). Cities in Transition. New Challenges, New Responsibilities. London: McMillan

Brans, J.P., Mareschal, B. (1994). The PROMETHEE-GAIA Decision Support System for Multicriteria Investigations. Investigation Operativa 4(2): 107-117

Camagni, R. (1991). Innovation Networks: Spatial Perspectives, London: Belhaven Press

Caragliu, A., Del Bo, C., Nijkamp, P. (2011). Smart Cities in Europe. Journal of Urban Technology 18 (2): 65-82

Diappi, L. (2012). Cities in the Era of the Knowledge Economy. In: R. Cappellin, F. Ferlaino and P. Rizzi (eds.), La Citta nell'Economia della Conoscenza. Milano: FrancoAngeli, pp. 137-146

Farr, D. (2008). Sustainable Urbanism. New York: John Wiley

Florida, R. (2002).The Rise of the Creative Class: and How it's Transforming Work, Leisure, Community and Everyday Life. New York: Basic Books

Hall, P. (2004). Cities of Tomorrow. Oxford: Blackwell

Healey, P. (2007). Urban Complexity and Spatial Strategies. London: Routledge

Ishizaka, A. and A. Labib, (2011), "Review of the main developments in the analytic hierarchy process", Expert Systems with Applications, Volume 38, Issue 11, Pages 14336-14345.

Jacobs, A.J. (2012). The World's Cities: Contrasting Regional, National and Global Perspectives. London: Routledge.

Jacobs, J. (1969). The Economy of Cities. New York: Random House

Komninos, N. (2000). Intelligent Cities. London: SPON Press.

Kourtit, K., Nijkamp, P. (2013). In Praise of Megacities in a Global World. Regional Science Policy and Practice (forthcoming)

Kourtit, K., Nijkamp, P., Suzuki, S. (2012) The Rat Race between World Cities: In Search of Exceptional Places by Means of Super-Efficient Data Development Analysis. Computers, Environment and Urban Systems 38: 67-77

Macharis, C., (2004). The Importance of Stakeholder Analysis in Freight Transport: The MAMCA Methodology. European Transport / Transporti Europei 25/26: 114-126

Macharis, C., Brans, J.P., Mareschal, B. (1998). The GDSS PROMETHEE Procedure - A PROMETHEE-GAIA based Procedure for Group Decision Support. Journal of Decision Systems 7: $283-307$

Macharis, C., Springael, J., De Brucker, K. and Verbeke, A. (2003). "PROMETHEE and AHP: the design of operational synergies in multicriteria-analysis. Strengthening PROMETHEE with ideas of AHP”, European Journal of Operational Research, 153, 2, 307-317.

Macharis, C., De Witte, A., Ampe, J. (2009). The Multi-Actor, Multi-Criteria Analysis Methodology (MAMCA) for the Evaluation of Transport Projects: Theory and Practice. Journal of Advanced Transportation 43(2), 183-202.

Mori Memorial Foundation (2012). Global Power City Index-2012. Tokyo

Munda, G. (2006). Social Multi-Criteria Evaluation for Urban Sustainability Policies. Land Use Policy 32 (1): 86-94

Nam, T., Pardo, T.A. (2011). Conceptualizing Smart City with Dimensions of Technology, People and Institutions. Proceedings of the 12the Annual International Conference on Digital Government Research. MD: College Park, pp. 282-291

Nanetti, R. (2012). Building the Future: Strategic Visions for American Cities and their Relevance for European Cities. In: R. Cappellin, F. Ferlaino and P. Rizzi (eds.), La Citta nell'Economia della Conoscenza. Milano: FrancoAngeli, pp. 147-168

Neal, Z. (2012). The Connected City. New York: Routledge 
Nijkamp, P. (2008). XXQ Factors for Sustainable Urban Development: A Systems Economics View. Romanian Journal of Regional Science 2 (1): 1-34

Nijkamp, P., Rietveld, P., Voogd, H. (1991). Multicriteria Analysis for Physical Planning. Amsterdam: Elsevier.

Rietveld, P. (1980). Multiple Objective Decision Methods and Regional Planning. Amsterdam: NorthHolland Publishers

Saaty T.L. (1982). Decision Making for Leaders. Lifetime Learning Publications. Wadsworth: Belmont

Sassen, S. (1991). The Global City, Princeton NJ: Princeton University Press

Taylor, P.J. (2004). World City Network. London: Routledge

Tranos, E., Nijkamp, P. (2013). The Death of Distance Revisited. Journal of Regional Science (forthcoming)

Winters, J.V. (2010). Why are Smart Cities Growing? Journal of Regional Science 20 (10): 1-18 